UNITED STATES

DEPARTMENT OF THE INTERIOR

GEOLOGICAL SURVEY

345 Middlefield Road

Menlo Park, CA 94025

A PORTABLE, LONG PERIOD

SEISMIC RECORDING SYSTEM

by

Douglas A. Stauber

Open-File Report

OF-82-836

February 1982

This report is preliminary and has not been reviewed for conformity with U.S. Geological Survey editorial standards.

Any use of trade names is for descriptive purposes only and does not imply endorsement by the U.S. Geological Survey. 
1. Introduction

This report describes the design, response, and calibration of a portable, long-period seismograph system. The system was designed to record teleseismic shear wave phases as well as broader band teleseismic $P$ waveforms than currently available on portable short-period systems. Before discussing the details of the system, a brief discussion of some reasons motivating the construction of this portable, long-period system will be given.

The successful use of teleseismic compressional (P) waves to delineate three-dimensional P-velocity structures in many cases (Steeples and Iyer, 1976; Aki, Christofferson and Husebye, 1977; Iyer et al., 1981; Oppenheimer and Herkenhoff, 1981; Reasenberg, Ellsworth and Walter, 1980; and Robinson and Iyer, 1981) leads one to inquire whether teleseismic shear (S) waves might be used in a similar manner to obtain threedimensional $S$ velocity models. Also, the modeling of long-period teleseismic $P$ and $S$ wave-forms has yielded information on $P$ and $S$ velocity structure beneath recording stations, Langston (1977, 1979, and 1981). Thirdly, phase velocities and polarization anomalies of surface waves can be modeled for $\mathrm{P}$ and $\mathrm{S}$ velocity structure of tectonic blocks greater than $625 \mathrm{~km}^{2}(25 \times 25 \mathrm{~km})$. Obtaining shear velocity models from the types of experiments suggested above in conjunction with $P$ velocity models from other experiments would allow stronger constraints on the composition and state of the earth than can be obtained from P-velocity models alone. The use of local earthquakes alone as $S$ wave sources 
would, in many areas, require a much longer recording time than would be required if teleseismic phases were utilized. The exclusive use of local earthquakes would also suffer from a poor distribution of source locations in many areas. It would be desirable, therefore, to have portable seismograph systems capable of recording teleseismic $S$ phases.

The short period seismic recording systems used in many of the teleseismic $P$ residual experiments and microearthquake networks in the western United States do not usually record clear teleseismic S phases. This limitation is due to the attenuation of shear waves in the upper mantle of the earth. The low frequencies of the teleseismic $S$ phases fall below the passband of these recording systems. A seismic recording system with a lower frequency passband (e.g. $0.02 \mathrm{~Hz}$ to $0.2 \mathrm{~Hz}$ ) than the current shorter period systems (typically above $1 \mathrm{~Hz}$ ) is necessary to obtain an adequate number of teleseismic $S$ wave recordings in a several month recording period. In addition, the system should be portable, require little construction at the deployment site, and not require servicing at intervals less than several days.

Daniel (1979) constructed and successfully used a seismic recording system fitting the requirements above to model the shear velocity structure at the Yellowstone Caldera, Wyoming. His recording system used the low-pass filtered output of a short period ( $1 \mathrm{~Hz}$ ) seismometer to obtain a system pass-band between 0.03 and $1.0 \mathrm{~Hz}$, where the output voltage was proportional to ground velocity in the pass-band. The recording system described in the present report uses the same technique to obtain a low frequency pass-band. The selsmometers have a larger 
natural period $(5 \mathrm{sec})$ and larger output voltages at low frequencies, than those used by Daniel (1979). The higher output of the current seismometers at low frequencies is exploited to extend the system pass-band to lower frequencies $(0.02 \mathrm{~Hz}$ compared to 0.03 in the system used by Daniel, 1979) and to make the output voltage proportional to ground displacement instead of ground velocity.

2. Description of the System

2.1. Geophone

Kinemetrics SV-1 and SH-1 intermediate-period seismometers are used to detect ground motion. These seismometers have velocity transducers, free periods of approximately 5 seconds and generator constants of about $150 \mathrm{volts} / \mathrm{meter} / \mathrm{sec}$. The tilt sensetivity is low enough that, in the normal field conditions (encountered during the field test described in a later section), a small plaster pad with an inset aluminum plate was sufficiently stable to keep the geophones centered for several weeks. Temperature variations pose a large problem, as a change of a few ${ }^{\circ} \mathrm{C}$ is enough to significantly change the mass position. An enclosure to prevent temperature varlations of the geophones of more than a few degrees centigrade must be provided.

Electromagnetic damping is provided by an external parallel combination of a shunt resister and the input impedance of the amplifier. The shunt resisters are located in the sefsmometer cables. The sefsmometers contain callbration colls which are used in calibrating the system. 
The nominal response of the seismometers to ground displacement is shown in Figure 1 for a damping parameter of 0.7 and a generator constant of 150 volts/meter/sec.

\subsection{Amplifier}

The signals from the seismometers are amplified by a 3-stage low-pass integrated-circuit amplifier. A schematic diagram is given in Figure 2. The first stage of the amplifier consists of a single-pole, low-pass differential input amplifier made up of $\mathrm{Al}, \mathrm{R} 1-\mathrm{R} 4, \mathrm{Cl}-\mathrm{C} 2$, and S1. The first stage has a gain of 100 and a corner frequency of 0.02 $\mathrm{Hz}$. The input impedance of $78.4 \mathrm{~K}$ Ohms is determined by resistors $\mathrm{RI}$ and R2 (Figure 2). Toggle switch $\mathrm{Sl}$ can be used to remove $\mathrm{Cl}$ and $\mathrm{C} 2$ from the circuit which results in a flat first stage response instead of it being a low-pass filter.

The output of the first stage is directly coupled to a second-order voltage-controlled-voltage-source (VCVS) low-pass filter, consisting of A2, R5-R9, C3-C4. The second stage has a gain of 10 and a corner frequency of $0.02 \mathrm{~Hz}$.

The output of the second stage is capacitively coupled to the third stage through capacitor C6 to remove DC offsets. Capacitor C6 and resistor $\mathrm{R} 10$ form a one-pole high-pass filter with a corner frequency near $0.005 \mathrm{~Hz}$, well below the $0.02 \mathrm{~Hz}$ corner frequencies of the first two stages. The third stage has a variable gain ( 1 to 124) which is selected by rotary switch 52 . The output impedance of the amplifier is controlled by A3, and, for the LM4250 chip used, is about 150 Ohms. 
The resistive and capacitive components which determine the corner frequencies of the amplifier stages one and two were chosen to have low temperature coefficients. Capacitors $\mathrm{Cl}, \mathrm{C2}, \mathrm{C} 3$ and $\mathrm{C} 4$ are polystyrene capacitors with temperature coefficients of less than $1 \times 10^{-4} /{ }^{\circ} \mathrm{C}$. The resistors in these two stages are metal film resistors with temperature coefficients also less than $1 \times 10^{-4} /{ }^{\circ} \mathrm{C}$. The changes in corner frequencies with a temperature change on the order of $10^{\circ} \mathrm{C}$ are, thus, expected to be less than $0.1 \%$. In the field test, the amplifiers were placed in a hole about $50 \mathrm{~cm}$ deep and covered with $25 \mathrm{~cm}$ of styrofoam to reduce diurnal temperature variations to less than $10^{\circ} \mathrm{C}$.

The amplitude and phase response of the amplifiers at full gain are plotted in Figure $3 \mathrm{~A}$ and the combined response of the seismometer and amplifier at full gain are plotted in Figure 4A. The combined response has it's maximum at $0.084 \mathrm{~Hz}$ and is roughly constant between 0.02 and $0.2 \mathrm{~Hz}$. Also shown in Figure $3 \mathrm{~B}$ and $4 \mathrm{~B}$ are the amplitude and phase response of the amplifier and seismometer-amplifer system with switch SI set to remove the filtering in the first stage of the amplifer. The system response, Figure $4 \mathrm{~B}$, now has its maximum at $0.20 \mathrm{~Hz}$ and the voltage out is roughly proportional to ground velocity in the pass-band.

\subsection{Power}

Power is supplied by an external 12 volt battery which runs a $D C-D C$ converter supplyfing regulated \pm 5.00 volts to the amplifiers. A schematic diagram of the power circuit is shown in Figure 2. 


\subsection{Recorder}

The portable, long-period system is comprised of the seismometers, amplifiers, power supply, and wiring harness, and is independent of the recording device. The analog USGS 5-Day recorders (Criley and Eaton, 1978) can easily be modified to record the long-period system signals along with three standard short-period signals. This modification was used in the field test and is described below. It is expected that the long period system output will be digitized and recorded on a digital field recorder in the future.

The amplifier-VCO cards within the 5-Day recorder system are modified so that the three long period signals are fed directly to the VCO input on the second channel of each card. Refer to Criley and Eaton (1978), Figures 9 and 10 for the locations of the following modifications which accomplish this objective. Jumper, SA, and resistors $\mathrm{R} 5$ and $\mathrm{R} 52$ are removed. A jumper wire is connected between pad $D$ and the common: A second jumper was connected between pad $\mathrm{C}$ and Monitor $\mathrm{J}$, the input to the VCO.

\subsection{Wiring Harness}

External wiring harnesses were constructed with 3 sockets for geophone lines to Kinemetrics SVI and SHI geophones and a standard 3component geophone line for the 5-Day recorder system. Short-period signals from $1 \mathrm{hz}$ geophone were connected, as in normal 5-Day recording system operation, to high gain amplifiers and were recorded on tape 
tracks 1,3 and 7 . The SVI and SHl geophone signals are routed to the long period amplifiers. The long period amplifier outputs are routed to VCO's on the second chanel of each 5-Day amplifier-VCO card and then to tape channels 2,4 and 6 by the wiring harness and the modifications of the 5-Day recorder cards described above. A schematic diagram of the wiring harness is given in Figure 5. It is expected that the wiring harness will be modified when recording systems other than the 5-Day recording system are used.

\subsection{Calibration Signal Generator}

The system is calibrated by applying a current to the calibration coils of the seismometer. A calibration circuit was built which supplies an arbitary 1024 point sequence of 16 levels ( 4 bit) of dc current to the calibration coils. This form of calibration signal was chosen because it allows the user flexibility in shaping the spectrum and is easy to generate. Since the times of tranisition between levels are easily syncronized to time sources for recording and digitizing systems one might use, no recording of the input calibration signals is needed to achieve precise phase calibrations. Additionally, to avoid aliasing when digitizing, one needs only to adequately sample the output of the portable long-period system, but not the input calibration current. The following paragraphs describe the calibration circuit and its operation. Later sections discuss the procedure for measuring the long-period system response from the digitized output of a calibration run and the details of the 1024 point calibration sequence actually used. 
Schematic diagrams of the calibration circuit are shown in Figures $6 \mathrm{~A}$ and $6 \mathrm{~B}$. A sketch 1llustrating the operation of the circuit in Figure $6 \mathrm{~A}$ is given in Figure 7 . This circuit is a modification of a circuit designed by Fred Fischer (personal communication, 1981). A 1024 point sequence of 4-bit words describing the time series which is to drive the calibration coils is stored in an ultraviolet-eraseable-programmableread-only-memory (UVEPROM) (IC3 in Figure 6A). The user may choose any such sequence by replacing IC3 with another UVEPROM chip which has been loaded with the desired sequence. The calibration sequence is started by a positive pulse applied through push-button switch 52 to pin 11 of IC2 (a binary counter). IC2 then sequentially addresses the memory chip IC3. The 4-b1t words stored in IC3 addressed by IC2 are latched by IC4 and are converted to analog form by the resistor network composed of resistors $\mathrm{R} 12$ through $\mathrm{R} 19$. The signal then passes through Al which isolates the output portion of the clrcuit which is shown in Figure $6 \mathrm{~b}$. The counter is clocked by an external square-wave clock signal. In the present system, the external clock signal comes from the time code generator of the USGS 5-Day recorder system (Criley and Eaton, 1978), which produces a $1 \mathrm{~Hz}$ square wave signal available on the front panel of the 5-Day recorder. This square-wave signal runs between 0 and -10 volts with downward transitions occurring at integral seconds. The external clock signal is inverted and reduced in amplitude to 6 volts by the wiring harness and resistors $R I$ and $R 2$ in Figure $6 \mathrm{~A}$. 
Gate 4 of ICl, R4 and $\mathrm{Cl}$ form a $50 \mathrm{khz}$ oscilator which can replace the external clock signal by switching $S 1$. This rapidly terminates (within $0.02 \mathrm{sec}$ ) the calibration sequence. Since the external clock is expected to run at $1 \mathrm{hz}$, a normal sequence would take more than 17 minutes to complete. Rapid termination is extremely useful when errors are discovered during a calibration sequence.

The circuit shown in Figure $6 \mathrm{~B}$ separates the signal produced by the circuit in Figure 6A into three channels (one for each component). The resister ladders on rotary switchs S3, S4 and S5, allow variable attenuation of the signals. Output buffers (A2, A3, A4) isolate signals in the three channels as well as reduce the signal levels by a factor of 0.4. At the outputs of $\mathrm{A} 2, \mathrm{~A} 3$ and $\mathrm{A} 4$, the voltage differences between adjacent levels (the digital step size) ranges from $2.78 \mathrm{mV}$ at the highest attenuation to 0.358 volts at the lowest attenuation. When toggle switch $\mathrm{S} 6$ is in the calibrate position the output of the A2, A3, and $A 4$ cause currents whose values are determined by $R 60, R 61, R 62$ and the calibration coil resistances. The calibration coil resistance for the Kinemetrics $\mathrm{SV}-1$ and $\mathrm{SH}-1$ seismometers are near $1.0 \mathrm{Ohm}$. Since resistors $R 60, R 61$ and $R 62$ are 2000 Ohms, much larger than the calibration coil resistances, the magnitude of the current flowing through the coils is primarily controlled by the voltage level of the output and the value of $R 60, R 61$ and $R 62$. Small variations in the calibration coil resistances are negligible. The difference in calibration coil current for adjacent voltage levels range from 1.39 uA at the highest attenuation to $0.171 \mathrm{~mA}$ at the lowest attenuation. 
When toggle switch $\mathrm{S6}$ is not in the calibrate position (normal operation of the station) the calibration coils are shunted by resistors R63, R64, and $R 65$ which have a value of 150 Ohms to approximate the output resistance of the output amplifiers A2, $A 3$ and $A 4$. This resistance causes negligable damping of the seismometers.

Power for the calibration clrcuit is supplied by two 9 volt transistor batteries connected in series. This 18 volts powers a regulated power supply which puts out \pm 3.62 volts, (Fred Fischer, pers. commun., 1981), which is used to supply the calibration circuit of Figure $6 \mathrm{~A}$ and $6 \mathrm{~B}$.

\section{System Response}

\subsection{Analytic Representation}

The transfer function of the individual elements of the seismic system, and the entire system, can be represented by expressions of the form

$$
\operatorname{tr}(w)=\sum_{j=0}^{n} N_{j} \cdot(i w)^{j} / \sum_{k=0}^{m} D_{k} \cdot(i w)^{k}
$$

where $\mathrm{N}_{j}$ and $\mathrm{D}_{k}$ are real constants and $\mathrm{w}$ is the frequency in radians per second. In this section, the values of $\mathrm{n}, \mathrm{m}, \mathrm{N}_{j}, \mathrm{D}_{k}$, will be determined for each component of the system, e.g. seismometer, amplifier, recorder, and playback. The transfer function of the entire system, also in the form of equation 1, can then be found as a product of the transfer functions of the separate components. 
The voltage out of an electromagnetic seismometer can be described as

$$
V(w)=\frac{G^{\cdot}(i w)^{3}}{(i w)^{2}+2 B w_{s} \cdot(i w)+w_{s}^{2}} X(w)
$$

where

$$
\begin{aligned}
& X(w)=\text { ground displacement } \\
& G \quad=\text { generator constant } \approx 150 \mathrm{v} / \mathrm{m} / \mathrm{s} \\
& B \quad=\text { damping factor } \approx 2^{-1 / 2} \\
& w_{S}=\text { resonant frequency } \approx 1.26 \mathrm{rad} / \mathrm{s}
\end{aligned}
$$

In this case $\mathrm{n}=3, \mathrm{~N}_{0}=\mathrm{N}_{1}=\mathrm{N}_{2}=0$, and $\mathrm{N}_{3}=\mathrm{G}$. Also, $\mathrm{m}=2$, $D_{0}=w_{s}^{2}, D_{1}=2 B w_{s}$, and $D_{2}=1$. These constants were used in calculating the response shown in Figure 1.

If the seismometer is driven by a current, $I(w)$ through its calibration coil, then the output voltage, $V(w)$ is

$$
V(w)=\frac{M G^{\cdot}(i w)}{(i w)^{2}+2 B w_{s} \cdot(i w)+w_{s}^{2}} I(w)
$$

where $M$ is a constant which depends on the mass and the force constant of the calibration coil. Nominal values of $M$ for the $S H-1$ and $S V-1$ sefsmometers are $8.2 \times 10^{-2} \mathrm{~m} / \mathrm{s}^{2}$ amp and $10.3 \times 10^{-2} \mathrm{~m} / \mathrm{s}^{2}$ amp, respectively. The denominator in equation 3 is the same as in 2 . In the numerator of equation $3, n=1, N_{0}=0$ and $N_{1}=M G$. 
The transfer function of the amplifier is easily derived from the transfer functions of the individual stages. Refer to Figure 2 in the following discussion. The first stage of the amplifier, consisting of $A 1, R 1$ through $R 4$, and $C 1$ and $C 2$, is elther an all pass or a single pole low-pass amplifler depending on the posistion of $\mathrm{Sl}$. If $\mathrm{Cl}$ and $\mathrm{C} 2$ are connected ( $\mathrm{SI}$ is closed), then the transfer function can be expressed as

$$
\frac{A_{1} w_{1}}{i w+w_{1}}
$$

where

$$
\begin{array}{ll}
A_{1}=R 3 / R I & =100.0 \\
w_{1}=1.0 / R 3 C 1 & =0.12755
\end{array}
$$

The second stage, comprising $A 2, R 5-R 9$, and $C 3-C 4$, is a second order, low pass, VCVS filter with a corner frequency near $0.02 \mathrm{~Hz}$, (Johnson and Hilburn, 1975), and has a transfer function

$$
\frac{A_{2} w_{2}^{2}}{(i w)^{2}+b_{1} \cdot(i w)+w_{2}^{2}}
$$


where

$$
\begin{aligned}
& \mathrm{A}_{2}=1.0+\mathrm{R} 7 / \mathrm{R} 8 \quad=1.005 \times 10^{1} \\
& w_{2}^{2}=1.0 / \mathrm{R} 5 \mathrm{R} 6 \mathrm{C} 3 \mathrm{C} 4 \quad=1.582 \times 10^{-2} \\
& b_{1}=(1.0 / R 5 C 3)+(1.0 / R 6 C 3)-(R 7 / R 8 R 6 C 4)=1.7601 \times 10^{-1} \\
& \text { Capacitor } \mathrm{C} 6 \text { and resistor } \mathrm{R} 10 \text { form a high-pass, single-pole filter }
\end{aligned}
$$

$$
\frac{i w}{i w+w_{3}}
$$

where

$$
\mathrm{w}_{3}=1.0 / \mathrm{C} 6 \mathrm{R} 10=3.0769 \times 10^{-2}
$$

The final stage, composed of $A 3, R 10-R 2 O$ and $S 2$, is a variable gain all-pass amplifier with a gain ranging between 1 and 124 in steps of approximately powers of two.

The total response of the amplifier is the product of equations 4 , 5, and 6 . It can be expressed as

$$
\frac{N_{1} \cdot(i w)^{1}}{D_{4} \cdot(i w)^{4}+D_{3} \cdot(i w)^{3}+D_{2} \cdot(i w)^{2}+D_{1} \cdot(i w)^{1}+D_{0}}
$$


where

$$
\begin{array}{lc}
\mathrm{N}_{1}=\mathrm{A}_{1} \mathrm{~A}_{2} \mathrm{~A}_{3} & 2.0278 \leq \mathrm{N}_{1} \leq 2.5141 \times 10^{2} \\
\left(A_{3} \text { depends on } \mathrm{S}_{2}\right) & 1 \leq \mathrm{A}_{3} \leq 124 \\
D_{0}=w_{1} w_{2}^{2} w_{3} & =6.2083 \times 10^{-5} \\
D_{1}=\left(w_{1}+w_{3}\right) w_{2}^{2}+b_{1} w_{1} w_{3} & =3.1953 \times 10^{-3} \\
D_{2}=w_{2}^{2}+b_{1} w_{1}+\left(b_{1}+w_{1}\right) w_{3} & =4.7615 \times 10^{-2} \\
D_{3}=b_{1}+w_{1}+w_{3} & =3.3437 \times 10^{-1} \\
D_{4}=1.0 &
\end{array}
$$

If switch S1, Figure 2, is open, the transfer function for the whole amplifier is found by the product of equations 5 and 6 . It can be expressed as

$$
\frac{N_{1} \cdot(i w)^{1}}{D_{3} \cdot(i w)^{3}+D_{2} \cdot(i w)^{2}+D_{1} \cdot(i w)+D_{0}}
$$

where

$$
\begin{array}{lrl}
\mathrm{N}_{1}=\mathrm{A}_{1} \mathrm{~A}_{2} \mathrm{~A}_{3} \mathrm{w}_{2}^{2} & 1.590 \times 10^{1} \leq \mathrm{N}_{1} \leq 1.971 \times 10^{3} \\
\mathrm{~A}_{3} & 1 \leq \mathrm{A}_{3} \leq 124 \\
D_{0}=w_{2}^{2} w_{3} & =4.867 \times 10^{-4} \\
D_{1}=w_{2}^{2}+\mathrm{b}_{1} w_{3} & =2.124 \times 10^{-2} \\
D_{2}=b_{1}+w_{3} & =2.068 \times 10^{-1} \\
D_{3}=1.0 &
\end{array}
$$

Responses calculated from equations 7 and 8 , are plotted in Figures $3 \mathrm{~A}$ and $3 \mathrm{~B}$. 
The transfer function of the combined amplifier and selsmometer is obtained by forming the product of equations 2 and 7 or 2 and 8 . These functions are plotted in Figure 4. The numerator polynomials have only one term, $\mathrm{GN}_{1} \cdot(1 \mathrm{w})^{4}$. The denominator polynomial is either a fifth or sixth order polynomial depending on whether equation 8 or 7 applies.

The response of the system to a current input to the seismometer calibration coils is described by the product of equation 3 with equation 7 or 8 . The numerator polynomials have only one term equal to $\operatorname{MGN}_{1} \cdot(i w)^{2}$. The amplitude and phase of the product of equation 3 with equation 7 are plotted in Figure 8. The maximum amplitude of this response occurrs near $0.02 \mathrm{~Hz}$ and it falls off proportional to $\mathrm{w}^{-2}$ between $0.02 \mathrm{~Hz}$ and $0.2 \mathrm{~Hz}$.

\subsection{Transfer Function From Calibration}

As we have just seen, the transfer function of the present seismograph system should be described by a ratio of two polynomials in (iw) with real coefficlents. The transfer functions of the system can be measured by forming the ratio of the spectra of the output of the system and a known current input into the calibration coils. This will not, generally, result in a smooth transfer function estimate since real earth motions which are also driving the system and electronic noise from the amplifiers, recording and playback processes add a random component to the observed output. An example of such a noisy transfer function is shown in Figure 9. A portion of the input signal to the calibration coil produced by the calibrator described earlier is plotted 
at the bottom of Figure 9. The form of this signal will be discussed in detail later. A corresponding portion of the output of the seismograph system is plotted above the input in Figure 9. The amplitude and phase of the ratio of the spectra of the two signals are plotted at the top of Figure 9 (crosses).

For many applications a smooth version of the transfer function, such as the smooth curves plotted in the top of Figure 9, is necessary. One way to achieve this smoothing is to fit a function with the theoretical functional form for the system to the noisy measured transfer function. As discussed earlier, the transfer function can be described by a ratio of two polynomials of finte order in powers of (1w) having real coefficients. The numerator polynomial has only one term and its constant can be absorbed into the denominator constants, without loss of generality. The order of the numerator term, power of (iw), is known so only the denominator coefficients must be solved for to fit the measured transfer function. If one works with the reciprocal of the transfer function, then the denominator polynomial coefficients can be solved for with a straightforward, linear, least-squares technique. If $o(w)$ is the output spectrum for an input current spectrum $I(w)$, one can wite

$$
o(w) \approx \frac{(i w)^{n}}{\sum_{k=1}^{m+1} d_{k} \cdot(i w)^{k-1}} I(w)
$$


Define $\operatorname{tr}(w)=o(w) / I(w)$ as the measured transfer function. In general, it will differ from the true transfer function because of the presence of noise from various sources. Equation 9 can then be rewritten

$$
\sum_{k=1}^{m+1} d_{k} \cdot(i w)^{k-1} \approx(i w)^{n / t r(w)}
$$

If discrete Fourier transforms are used to obtain $o(w)$ and $I(w), \operatorname{tr}(w)$ will usually be evaluted at many more values of $w$ than there are coefficients $d_{k}$, so equation 10 results in an over determined linear system of equations.

$$
\sum_{k=1}^{m+1} A_{j j} d_{k}=\left(i w_{j}\right)^{n / t r} j
$$

where

$$
\begin{aligned}
& A_{j k}=\left(i w_{j}\right)^{k-1} \\
& t r=t r\left(w_{j}\right) \\
& d_{k}=m+1 \text { real coeficients } \\
& j=\text { ranges over the number of frequencies, and } \\
& m+1 \text { is the order of the denominator polynominal necessary to } \\
& \text { describe the transfer function. }
\end{aligned}
$$


In the following equations, capital letters will refer to matricies and small letters will refer to vectors or scalars; vectors are distinguished from scalors by context. Definitions are given, as new quantities are introduced. Superscripts "*" and " $T$ " mean complex conjugate and transpose, respectively. It is convenient to replace the right hand side of equation 11 with $x_{j}$ where

$$
\begin{aligned}
& x_{j}=\left(i w_{j}\right)^{n} p_{j} / t r \\
& j \\
& \text { and } \quad p_{j}=p\left(w_{j}\right)
\end{aligned}
$$

$p(w)$ includes the transfer function of the recording, playback and digitizing processes and is assumed to be known from previous measurement. In the cases presented here, $p(w)$ is relatively flat over the passband of the seismometer-amplifier system and not expected to change much with time. Let $\epsilon$ be defined as the error vector for equation 11 .

$$
\epsilon=\mathrm{x}-\mathrm{Ad} \quad \text {. }
$$

$\chi$ is the euclidean length of $\epsilon$

$$
\chi^{2}=\epsilon^{T *} \epsilon=x^{T^{*}} x+d^{T} G d-\left(x^{T^{*}} A d+d^{T} A^{T^{*}} x\right)
$$

where

$$
G=A^{T *} A
$$


20

Minimizing $\chi^{2}$ and using $G_{k j}=G_{j k}^{\star}$ and $x^{T^{*}} A=\left(A^{T^{*}} x\right)^{*}$ yields

$$
\frac{\partial \chi^{2}}{\partial d}=0=2 H d-2 \operatorname{real}\left(A^{\star} T_{x}\right)
$$

where $H=\operatorname{real}[G]$ and is a real, symmetric $(m+1)$ by $(m+1)$ matrix. Then

$$
d=H^{-1} \operatorname{real}\left(A^{\star} T_{x}\right)
$$

The matrix $\mathrm{H}$ is easily computed and has the form

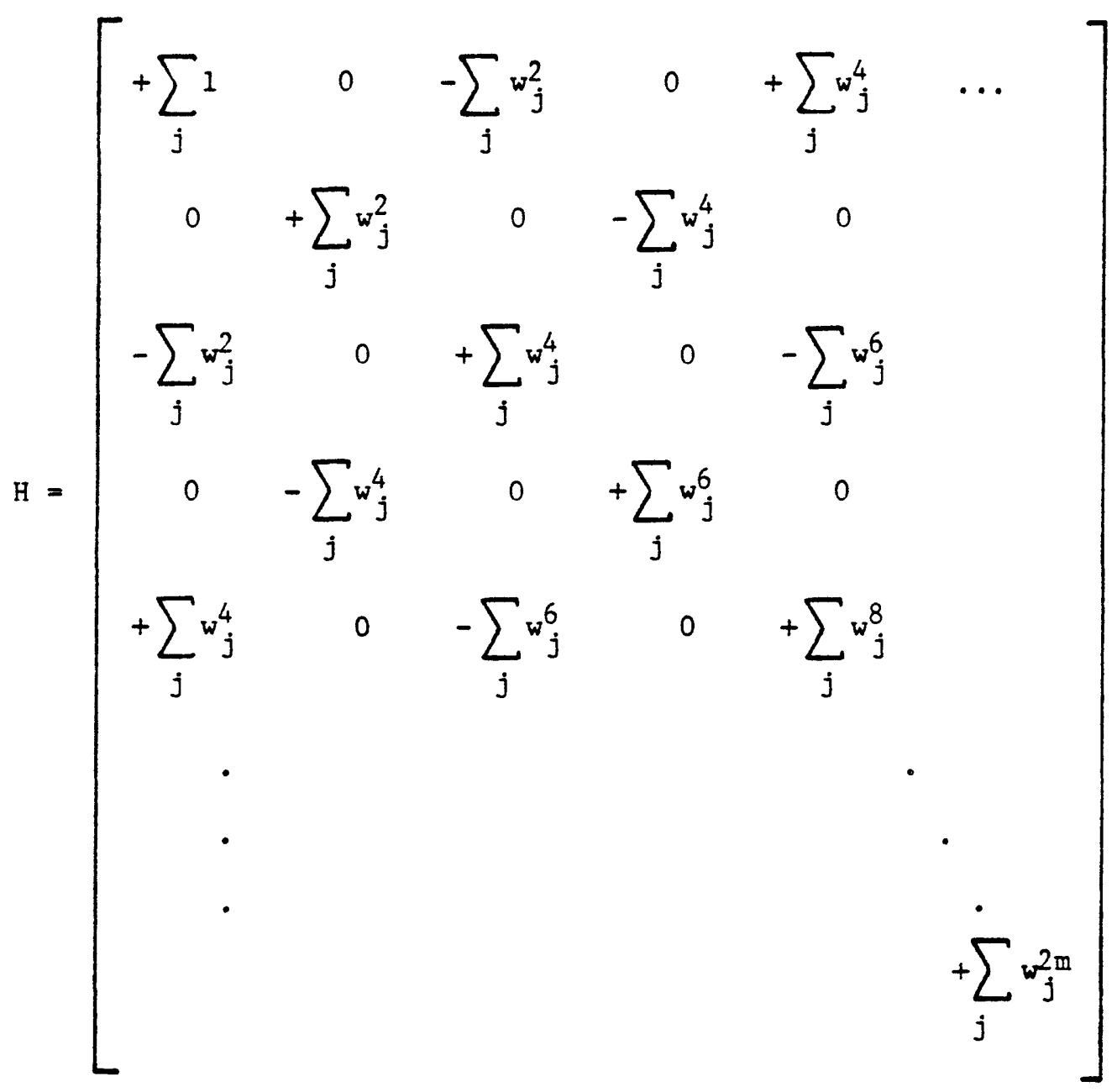




$$
H_{a b}=0.5(-1)^{((3 a+b-4) / 2)}\left(1+(-1)^{a+b-2}\right) \sum_{j=1}^{J} w_{j}^{(a+b-2)}
$$

and

$$
\operatorname{real}\left(A^{\star} T{ }\right)_{k}=\operatorname{real}\left((-1)^{k-1}\left(i w_{j}\right)^{k+n-1} p_{j} / t r_{j}\right)
$$

The inverse of matrix $\mathrm{H}$ is easily obtained using standard routines from the IMSL library of programs. In practical examples for the present system, inversion of $\mathrm{H}$ has been very stable and led to reasonable results without resorting to sophisticated methods of matrix inversion. In practice, it was useful to weight equation 11 by the recriprocal of the magnitude of the nominal denominator polynomial (calculated from equations 3 and 7 or 8 using nominal component values) to obtain a uniform quality of fit across the whole passband of the system. If the magnitude of the nominal denominator polynomial at frequency $w_{j}$ is $r_{j}$, then equations 18 and 19 become

$$
H_{a b}=0.5(-1)^{((3 a+b-4) / 2)}\left(1+(-1)^{a+b-2)} \sum_{j=1}^{J} w_{j}^{(a+b-2)} / r_{j}^{2}\right.
$$


and

$$
\operatorname{real}\left(A^{\star} T_{X}\right)_{k}=\operatorname{real}\left((-1)^{k-1}\left(i w_{j}\right)^{k+n-1} P_{j} /\left(t r_{j}{ }_{j}^{2}\right)\right)
$$

An example of this fitting procedure is shown in Figure 9. The smooth solid curve which passes through the observed transfer function was calculated from a polynomial representation whose coefficients were derived from the observed transfer function by the method described above. The computed coefficients are listed in Table 3 along with the nominal values for comparison. Comparison of the observed and computed transfer function in Figures 9 shows that the 8 real coefficients given in Table 3 are adequate to describe the transfer function of the amplifier and seismometer across the entire passband.

The reason that 8 coefficients are required to produce the good fit shown in Figure 9 instead of the 7 coefficients expected (see table 3 ) is not known. The improvement in the quality of the fit between 7 and 8 coefficients, however, justifies the use of the additional coefficient. The Fortran program used to calculate the coefficients is listed in Appendix A.

\subsection{Calibration Signal}

The calibration current signal is described by 1024 4-bit words and a portion of the signal is plotted in Figure 9. The signal is derived from a random binary signal which has the desirable properties of 
containing power over a broad frequency band and having the power uniformly distributed in time. For the present seismic system, for which the transfer function falls off as $\mathrm{w}^{-2}$ above $0.02 \mathrm{~Hz}$ (see Figure 8 ), the output power produced by a random binary input becames swall relative to the background noise at the high frequency end of the passband, near $0.2 \mathrm{~Hz}$. It is necessary to modify the random binary signal to increase the spectral power near $0.2 \mathrm{~Hz}$. This was accomplished by passing a random binary sequence through a one-pole, high-pass filter with a corner frequency at $0.2 \mathrm{~Hz}$ and then digitizing the output to 14 levels. To keep the average input power as high as possible, a 512-point sequence generated in this manner was repeated twice to form a 1024-point sequence to load into the memory of the calibrator circuit. By using the spectrum of the system output for the second half of the sequence (512 to 1024 seconds from the start of the calibration signal) the approximation of periodicity made by discrete fourier transforms is almost exactly observed. The first 512-second segment is long enough to allow the transients caused by start-up to decay to negligable levels. The 512-point calibration sequence used in the example shown in Figure 9 is listed in Table 4.

4. System Noise, Detection Threshold and Dynamic Range An example of the noise generated by the amplifier electronics is shown in the bottom of Figure 10. To obtain this noise sample the inputs to the amplifer were shunted with a $5 \mathrm{~K}$ Ohm resistor, approximating the coil resistance of the seismometers and the gain was 
set to its maximum value. There is clearly long-period noise with an amplitude of about $50 \mathrm{mV}$. The amplitude of the spectrum of the noise signal on the bottom of Figure 10 is plotted in the top of the figure. The noise amplitude increases as frequency decreases at a rate approximately proportional to $\mathrm{w}^{-1}$. The solid line through the spectral amplitudes has a slope of $\mathrm{w}^{-1}$ and is a visual fit to the noise amplitude spectrum. This linear segment which passes through 18.3 $\mathrm{mV}$ at $0.02 \mathrm{hz}$ and $1.83 \mathrm{mV}$ at $0.2 \mathrm{hz}$ will be used to approximate the nolse amplitude spectrum in the following analysis. The amplifiers have a full range of \pm 4.0 volts so the useful dynamic range of the amplifiers at maximum gain ranges from $47 \mathrm{db}$ at $0.02 \mathrm{~Hz}$ to $67 \mathrm{db}$ at 0.2 $\mathrm{Hz}$. Since the noise was found to originate primarily in the first stage of the amplifier and the gain is adjusted at the last stage, the dynamic range will increase as the gain is reduced. However, when using the 5-Day recording system, the noise level of the recording and playback process precludes the use of an amplifier gain reduction to increase the dynamic range.

The amplifier noise level also sets the minimum detection threshold for the system. Using the solid line with slope $w^{-1}$ of Figure 10 as representative of the amplifier noise level, and using the nominal values of the seismometer and amplifier responses, given in equations 2 and 7 , respectively, the equivalent ground displacements of the system noise are calculated and plotted in Figure 11. Also shown in Figure 11 is the background earth noise from a quite site (Peterson and Orsin1, 1976) and the detection threshold for a WWSSN long period seismograph 
station. Over the passband of the present system, $0.02 \mathrm{~Hz}$ to $0.2 \mathrm{~Hz}(5$ to 50 seconds period), the detection thresholds of the present system and the WWSSN station, operated a magnification of 3000 , are comparable. The present system is more sensitive at $0.2 \mathrm{~Hz}$ and a $11 \mathrm{ttle}$ less sensitive at $0.02 \mathrm{~Hz}$. Both system detection thresholds are well above the earth noise levels at $0.02 \mathrm{~Hz}$. The expected magnitudes of 20 second period surface waves for a shallow teleseism $60^{\prime}$ from the seismograph, taken from Richter (1958, page 346), are shown with circles. The minimum magnitude detectable by the portable system is about 4.4. At maximum gain, the system will be saturated for $M_{S}=$ 7.1 at 60 degrees. Teleseismic $S$ waves observed on the portable system typically have periods of 15 to 20 seconds (see Figure 12). The expected amplitude for $S$ waves for a magnitude 5 earthquake at $60^{\prime}$ is shown by the small cross hatched area on Figure 11 . These were calculated from Figure VIII-7 of Richter (1958). The vertical range is caused by variation in focal depth between 0 and $600 \mathrm{~km}$. Clearly, at a distance of 60 degress, the minimum useful magnitude for shear body waves is about magnitude 5. The detection threshold of 4.5 to 5.0 for the $S$ phases is about the same as the body wave magnitude detection threshold of 4.5 to 5.0 found for short period teleseismic $P$ waves in experiments in the western U.S. Consequently, one can expect a similar rate of accumulation of useful recordings.

\section{Field Test}

Four three-component systems were built and deployed in the Mt. Lassen, California, area for a two-month field trial in the fall of 
1980. At each site, a hole measuring approximately $50 \mathrm{~cm}$ on a side was dug into the soll. Plaster of Paris was poured to form three pads slightly larger then the geophones and a 1/8" aluminum plate was set in each pad before it hardened. The geophones sat on the aluminum plates. Plywood sides were built around the sides of the vault and soil removed from the hole was backfilled around the sides of the plywood. A $25 \mathrm{~cm}$ thick slab of styrofoam was placed in the plywood frame over the seismometers to provide thermal insulation and the top was covered with a plywood 1id. In these crude vaults, the seismometers were stable and, after the first few days, were able to run without recentering for more than a month. The amplifiers were similarly burled, insulated, and were seldom disturbed during the experiment.

An example of a teleseism recorded by the long period system is shown in figure 12. Also shown are the three components of a normal 5-Day recorder system (Criley and Eaton, 1978.) The event ocurred in Algeria, about $87.5^{\circ}$ from the recording station. The waves approach the recording site from the northeast. The long-period horizontal geophones were orlented $N 45^{\circ} \mathrm{E}$ and $N 45^{\circ} \mathrm{W}$ making them almost radial and transverse components for this event. The short-period geophones were oriented north and east.

Both $P$ and PP and multiple body-wave $S$ phases are clearly visible on the long-period vertical and horizontal traces. The event shown in figure 12 is unusual in that clear $S$ waves with a dominant period of 4 seconds are visible on the short period traces. These are not typically observed. A dispersed Rayleigh wave train is visible on the long period 
vertical channel. It is slightly clipped on the vertical channel for periods near $20 \mathrm{sec}$ as expected from the magnitude and distance. This example demonstrates that teleseismic $P$ and $S$ body-wave phases and Rayleigh waves suitable for the kinds of experiments discussed in the introduction can be recorded by the portable long-period system. 
Table 1

Component values for Amplifier

$R 1, R 2$
$R 3, R 4, R 16$
$R 5$
$R 6$
$R 7$
$R 8$
$R 9, R 12$
$R 10, R 11, R 20$
$R 14, R 15$
$R 17$
$R 18$
$R 19$
$R P 1, R P 2$
$C 1, C 2$
$C 3, C 4$
$C 5$
$C 6$
$C 20$
$C 21, C 22$

Al

$\mathrm{A} 2, \mathrm{~A} 3$

D1
$39.2 \mathrm{~K}$ Ohms

$3.92 \mathrm{M}$ Ohms

$442 \mathrm{~K}$ Ohms

$5.74 \mathrm{M}$ Ohms

$10.5 \mathrm{M}$ Ohms

$1.21 \mathrm{M}$ Ohms

4.75 M Ohms

130 K Ohms

$8.06 \mathrm{M}$ Ohms

$1.91 \mathrm{M}$ Ohms

$909 \mathrm{~K}$ Ohms

$383 \mathrm{~K}$ Ohms

$100 \mathrm{~K}$ Ohms

$2.0 \mathrm{uF}$

$5.0 \mathrm{uF}$

$1.0 \mathrm{uF}$

$250 \mathrm{uF}$ (two $500 \mathrm{~F}$ in

series)

$100 \mathrm{uF}$

200 uF tantalum capacitors

in parallel with

0.15 uF ceramic capacitors

PMI OP07 $C$ made by Precision Monolithic, Inc.

IM4250

DIP120505DP Intergrated

circuits Incorporated \pm 5.0

volt, $D C-D C$ convertor 
Table 2

Component values for calibrator

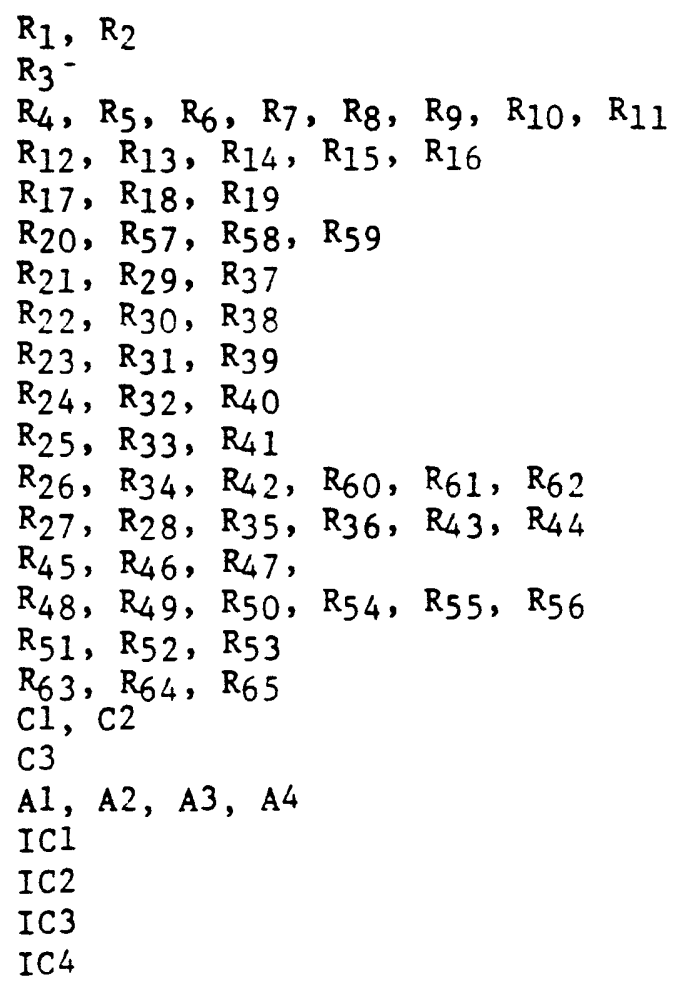

$500 \quad \mathrm{~K}$ Ohm 1 M Ohm

$100 \mathrm{~K}$ ohm

$442 \mathrm{~K}$ ohm

$221 \mathrm{~K}$ ohm

$5 \quad \mathrm{MOhm}$

$64.8 \mathrm{~K}$ ohm

$32.4 \mathrm{~K}$ ohm

$16.2 \mathrm{~K}$ Ohm

$8.06 \mathrm{~K}$ ohm

$4.02 \mathrm{~K}$ ohm

$2.00 \mathrm{~K}$ Ohm

$1.00 \mathrm{~K}$ ohm

720 K Ohm

402 K ohm

$499 \quad \mathrm{~K}$ Ohm

150 Ohm

$500 \quad \mathrm{pF}$

0.1 uF

LM4250

$\mathrm{CD} 4093$

CD4040

IM6653

MM74C173 
Table 3

Nominal and computed polynominal coefficients describing the transfer function of Figure 9 .

Amplifier x Geophone

playback $x$ digitizer

$\left(\frac{(i w)^{2}}{d_{8} \cdot(i w)^{7}+d_{7} \cdot(i w)^{6}+\ldots+d_{1}}\right)$

$\left(\frac{p_{4}}{p_{3} \cdot(i w)^{2}+p_{2} \cdot(i w)+p_{1}}\right)$

nominal

computed

$d_{1} \quad 2.5997 \times 10^{-9}$

$1.4043 \times 10^{-10}$

$d_{2} \quad 1.363 \times 10^{-7}$

$1.7924 \times 10^{-8}$

$d_{3} 2.1461 \times 10^{-6}$

$2.9196 \times 10^{-7}$

$d_{4} \quad 1.6330 \times 10^{-5}$

$2.6879 \times 10^{-6}$

$d_{5} \quad 5.8895 \times 10^{-5}$

$1.0392 \times 10^{-5}$

$d_{6} 5.5993 \times 10^{-5}$

$1.4113 \times 10^{-5}$

d $2.6518 \times 10^{-5}$

$8.6148 \times 10^{-6}$

$d_{8} \quad 0.0000 \times 10^{0}$

$3.8750 \times 10^{-6}$

$P_{1} \quad 5.685 \times 10^{1}$

fixed at nominal value

$\mathrm{P}_{2} \quad 1.066 \times 10^{1}$

fixed at nominal value

$\mathrm{P}_{3} \quad 1.000$

fixed at nominal value

$\mathrm{P}_{4} 5.685 \times 10^{1}$

fixed at nominal value 
în ar î $\vec{i}$ i बभน

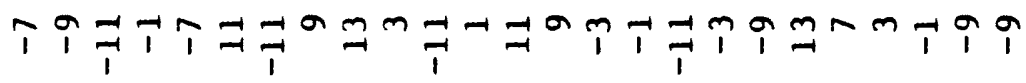

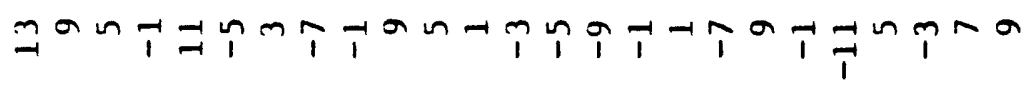

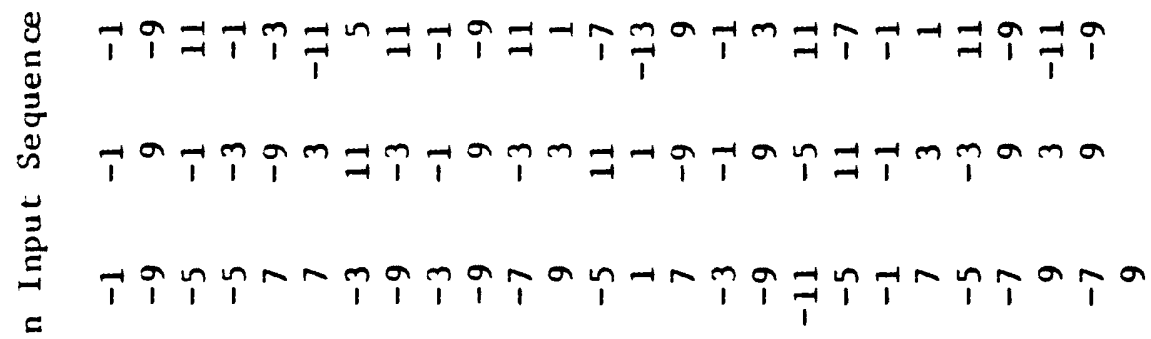
$\stackrel{2}{2}$ का वो n 引马 n $\hat{\imath} m$ n

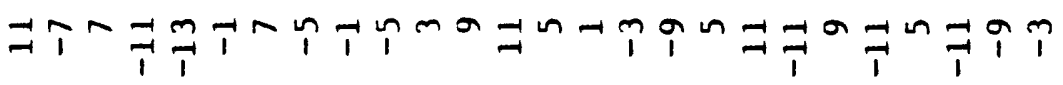

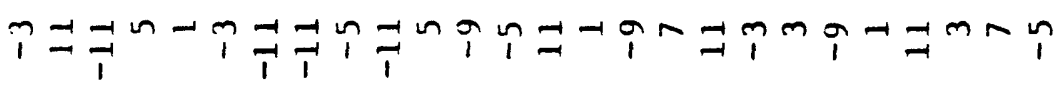
$\hat{\imath} \vec{\imath}=-\hat{\imath}$ 的

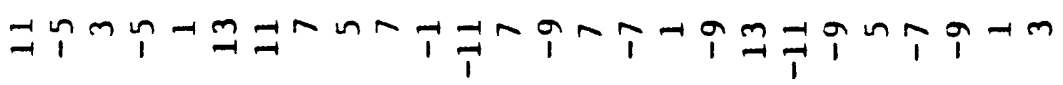

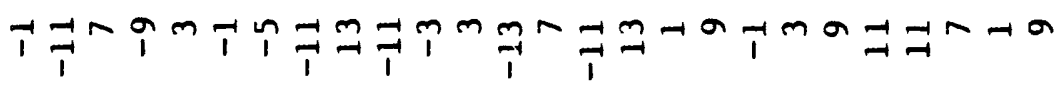

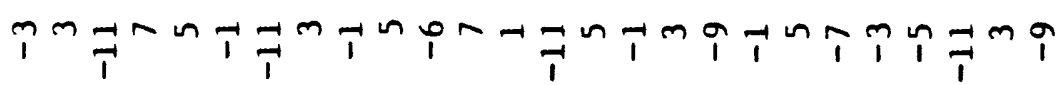

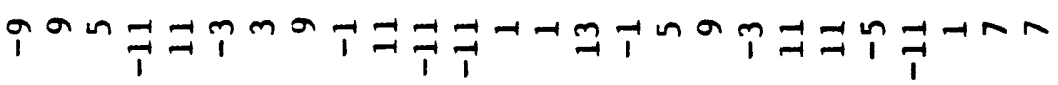




\section{References}

Aki, Keilti, Anders Christoffersson, and Eystein S. Husebye, Determination of the three-dimensional seismic structure of the 11thosphere, Jour. Geophys. Res., 82, 277-296, 1977.

Criley, Ed and Jerry Eaton, Five-day recorder seismic system, U.S. Geological Survey Open-File Report 78-266, 1978.

Daniel, R.G., Evaluation of intermediate-period seismic waves as a geothermal exploration tool, Ph.D. Thesis, Dept. of Geophysics, Stanford University, 1979a.

Daniel, R.G., An intermediate-period field system using a short-period field system using a short-period seismometer, Bull. Seismol. Soc. Am. , 69, 1623-1626, $1979 b$.

Iyer, H.M., J.R. Evans, G. Zandt, R.M. Stewart, J.M. Coakley, and J.N. Roloff, A deep low-velocity body under Yellowstone caldera, Wyoming: delineation using teleseismic $P$-wave residuals and tectonic interpretation: Summary, Geol. Soc. of Am. Bull., Part 1, 92, $792-798,1981$.

Johnson, David E. and John L. Hilburn, Rapid practical designs of active filters, John Wiley and Sons, New York, 264.p, 1975.

Langston, C.A., Corvallis, Oregon, crustal and upper mantle receiver structure from teleseismic $P$ and $S$ waves, Bull. Seismol. Soc. Am., $67,713-724,1977$.

Langston, C. A., Structure under Mount Rainier, Washington, inferred from teleseismic body waves, J. Geophys Res., 84, 4749-4762, 1979.

Langston, Charles A., Evidence for the subducting lithosphere under southern Vancouver Island and western Oregon from teleseismic $P$ wave conversions, J. Geophys. Res., 86, 3857-3866, 1981. 
Oppenheimer, D.H. and K.E. Herkenhoff, Velocity-density properties of the lithosphere from three-dimensional modeling of the Geysers-Clear Lake region, California, Jour. Geophys. Res., 86, 6057-6065, 1981. Peterson, Jon and Nicholas A. Orsini, Seismic research observatories: upgrading the worldwide seismic data network, Trans. Am. Geophys. Union, 57, 548-556, 1976.

Reasenberg, P., W. Ellsworth and A. Walter, Teleseismic evidence for a low-velocity body under the Coso Geothermal area, J. Geophys. Res., $85,2471-2484,1980$.

Richter, Charles F., Elementary Seismology, W.H. Freeman and Company, San Francisco, 768p., 1958.

Robinson, R. and H.M. Iyer, Delineation of a low-velocity body under Rosevelt Hot Springs Geothermal Area, Utah, using teleseismic $P$-wave data, Geophysics, 1456-1466, 1981 .

Steeples, Don W. and H.M. Iyer, Low-velocity zone under Long Valley as determined from teleseismic events, J. Geophys. Res., 81, 1976. 
This program fits a sransfer function of the form $\operatorname{tr}(w)=N(\{w\} / D(f w)$ to a set of observed values of $t r(w)$. $N(1 w)$ is defined and calculated by subroutine numpol. $D(1 w)$ is a polynomial in ( Iw) of order $(1-1)$ with 1 ( 1 less than 11) real coeficlents which are found by the program. The input transier function 1 s expected as complex values consecutiveiy at irequencies $(j-1)$ *d $y$ where $j$ ranges from $j 1$ to $j 2$. The problem 15 formulated as $H x=y$ where $H$ and $y$ are known. $x$ is a vestor of the 1 real denominator polynomial coefficlents to be found.

The equations are dividad by their esiectud maginicudes, computed by subroutine denpol, so they have approximately equal magnitudes. The solution, $x$, is found by IMSL subroutine LEGTIF and $i=$ stored in place of $y$.

double precision $h(15,10)$, wharea $(150), y(10)$

double precision hl, dr,w

real $\operatorname{tr} 1(2, j \pi)$

complex trizas), en, cy,ci, wh

character*eis chr

data h/igis:-.j/, y/1000.J/

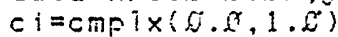

write $(6,900)$

900 formati enter number of coefficients, $12^{\prime}$ )

read $(5,951)$ ?

901 format $(i 2)$

write $(6,9) 1) 1$

writelc, sivis

gas format ' enter starting and endins frequency points,215') $\operatorname{read}(5,9 g 7) j 1 . j 2$

9a7 format 215$)$

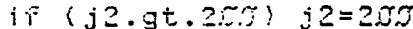

witis( $6,3,7)$ j!,$j$ ?

do $5 i=1,8$

read $(5,:(=39)+)$ chr

5 wirite(b, (a) $a)$, chr

$c$ read anguiar freguncy step read $(5,9 \%)$ d

904 formatiele. writei $6,92 i$ ) dit read observed transfer function read(5, 9iis)ir

903 format 2 iej 15.3$)$

c compute ecuation weights do 1 lo $j=j i, j 2$ $w=(j-1): d w$ cali denpol(w,en)

16 ir $\{(j)=(r \geqslant a\}(c a)) * 2 \div(a\{m a g(c n)) * * 2$ $w n=\operatorname{cinp} 1 \times(1 . ., \varnothing . \mathscr{D})$ compuse H n= do $5, j \mathrm{~m}=1, i$ $h 1=\mathfrak{D} . \mathfrak{D}$

c compute diagonal value of $H$ do $1 \sum \delta j=j 1, j 2$

$1006 h l=h 1+(; 10 a t(j-1)\} * *\{102 t(2 * m-2)\} * \operatorname{tr} 1(j)$

$h(m, m)=h: *(d w *(2 * m-2))$

c compute off-diagonal values of $\mathrm{H}$ $n=m-1$

$11=(i-1) / 2$

if $(n . g t .11) \quad n=1-m$

do $15 \tilde{x} i=1, n$

$\mathrm{mm}=\mathrm{m}-\dot{i}$

$m p=m \div 1$

$h(m m, m p)=h(m, m) *((-1) * * i)$

$152 h(m p, m a)=h(m m, m p)$ 


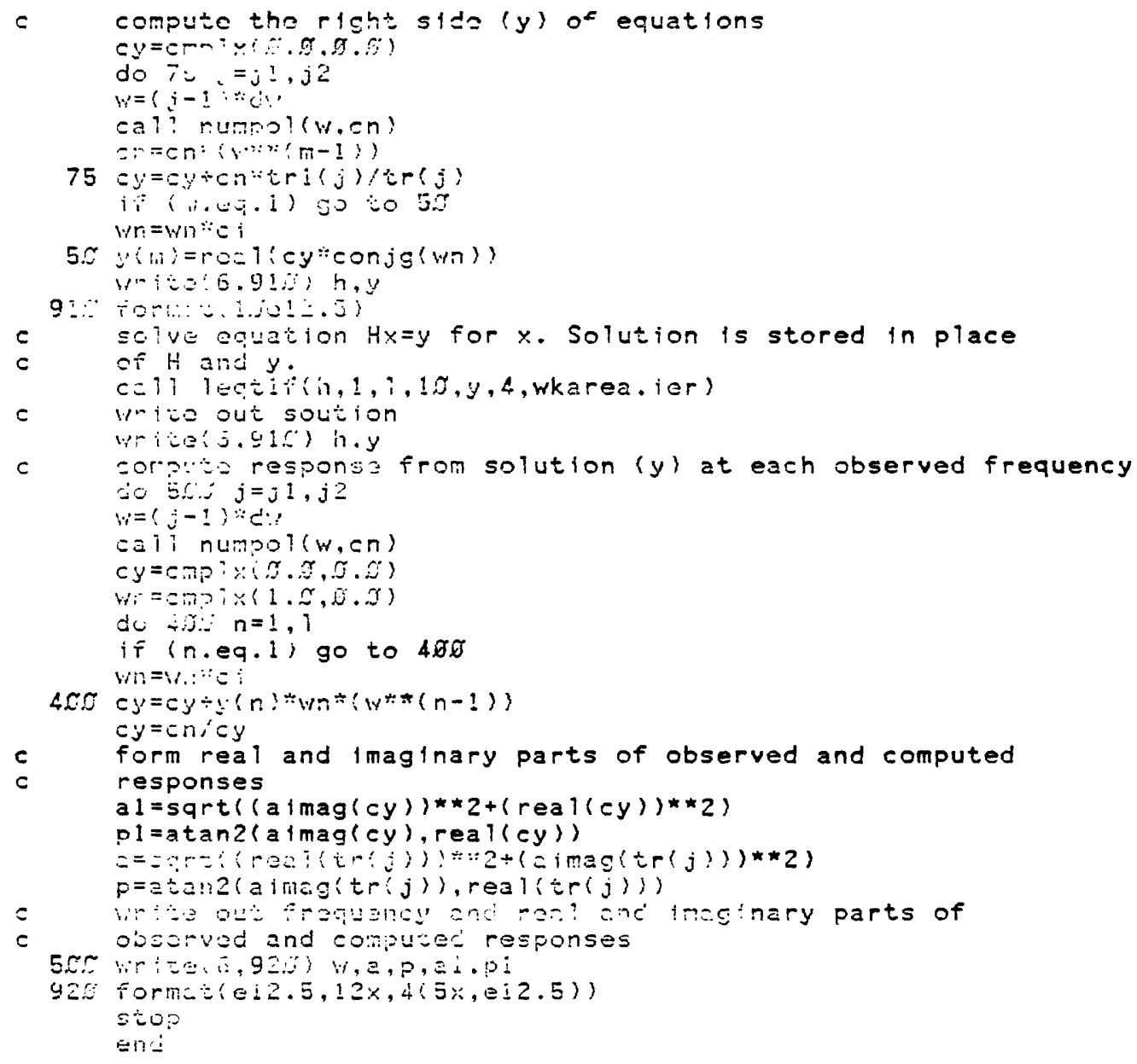




\section{subroutine numpo: $(w . t)$}

c This subcuind avaluates the complex combined numerator

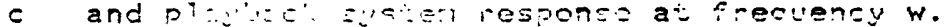

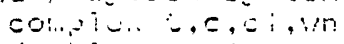

dounis nineis.an $n(5) . d: 5), w$

dEt: $n / 3, \therefore, 0.0,-39.4734: 7.9 .0,5.01$

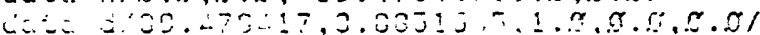

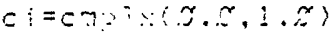

$\therefore \because$.

$c=$

$w r=1 . S$

$\mu r=c \pi r] \times\{1.0, \pi, \pi\}$

$0 \quad 1, \therefore \quad i=:, 5$

i: $: .0 \%: 0= \pm 01 \%$

Wii: $=\pi, i=$

$\forall=: ;$

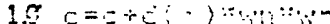

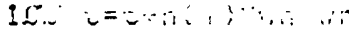

$t=\div !$

revuin

e.ic

\footnotetext{
subrout ine denpol $(w, c)$
}

c This subroutine evaluates the nominal denominator polyriomial

c for the portable, long-pertod system response at frequency $w$. real a (10)

double precision $w$

complex $c$

data $a / 2.5997 e-99,1.363 e-97,2.146 i e-06,1.633 e-\$ 5,5.8895 e-\$ 5$,

1 $5.59030-05,2.6513 e-55,5.6 i, \tilde{U} .0, \varnothing . \infty 1$

$c=c m p l \times(-a(7) *(w * * G)+a(5) *(w * * 4)-a(3) *(w * * 2)+a(1), \varnothing . \varnothing)$

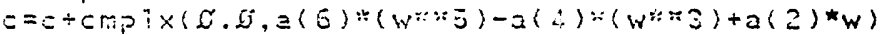

$c=1.0 i c$

return

elic 
Figure Captions

Figure 1. Nominal amplitude response for a geophone with a free period of 5 seconds, damping factor of 0.7 , and a generatior constant of $150 \mathrm{volts} / \mathrm{meter} / \mathrm{sec}$.

Figure 2. Amplifier schematic. Component values are listed in Table 1. Figure 3. Amplifier response. Amplitude response is plotted with ' + ' symbols and phase response is plotted with dots.

a) SI is switched so that first stage of amplifier is a low-pass filter with a corner frequency of $0.02 \mathrm{~Hz}$. The entire amplifier acts as a low-pass filter which falls off at $18 \mathrm{db} /$ octave above $0.02 \mathrm{~Hz}$. Equation 7 is used to calculate the response.

b) SI is switched so that first stage of has a flat response. The entire amplifier falls of at $12 \mathrm{db} /$ octave above 0.02 Hz. Equation 8 is used to calculate the response.

Figure 4. System response, seismometer times amplifier. Amplitude is plotted with ' + ' symbols and phase is plotted with dots.

a) First stage of amplifier is switched to a low-pass filter. b) First stage of amplifier is switched to a flat amplifier.

Figure 5. Wiring diagram of wiring harness for use with "5-Day recorder" system.

Figure 6. Schematic diagram of calibration circuit. Component values are given in table 2 .

a) signal synthesis section.

b) output section.

Figure 7. Illustration of function of the circult shown in figure $6 \mathrm{a}$. 
Figure Captions (continued)

Figure 8. Nominal amplitude and phase of transfer function of amplifier-seismometer system for current inputs to the calibration coil. ' + ' = amplitude, '.' = phase.

Figure 9. Calibration example. The first 256 points of the current input to the calibration coil is shown at the bottom. The corresponding output of the amplifier is shown above. The ratio of the spectra of the two signals is plotted in the top half of the figure with ' + ' symbols. The smooth curves passing through the data were calculated by the fitting routine described in the text.

Figure 10. Bottom trace shows an example of the system noise. The amplitude of the spectrum of this signal is plotted above. The solid line passing through these points on the right has a slope of $w^{-1}$ and is a visual fit.

Figure 11. The background earth noise at a quiet site from Peterson and Orsini (1967) is shown with a solid line. Detection thresholds of the portable long-period system and a WWSN long-period system are shown with a solid and a dashed curve. Amplitudes of 20-second surface waves for various magnitude events at a distance of $60^{\circ}$ are plotted with circles and are taken from Richter (1958). The cross-hatched parallelogram shows the expected amplitudes of $S$ body waves for a magnitude 5 event at $60^{\circ}$ (also from Richter, 1958). 
Figure Captions (continued)

Figure 12. Sample playback of a teleseism recorded by both the USGS

"5-Day recorder" system, SP, and the portable long period system, LP. 


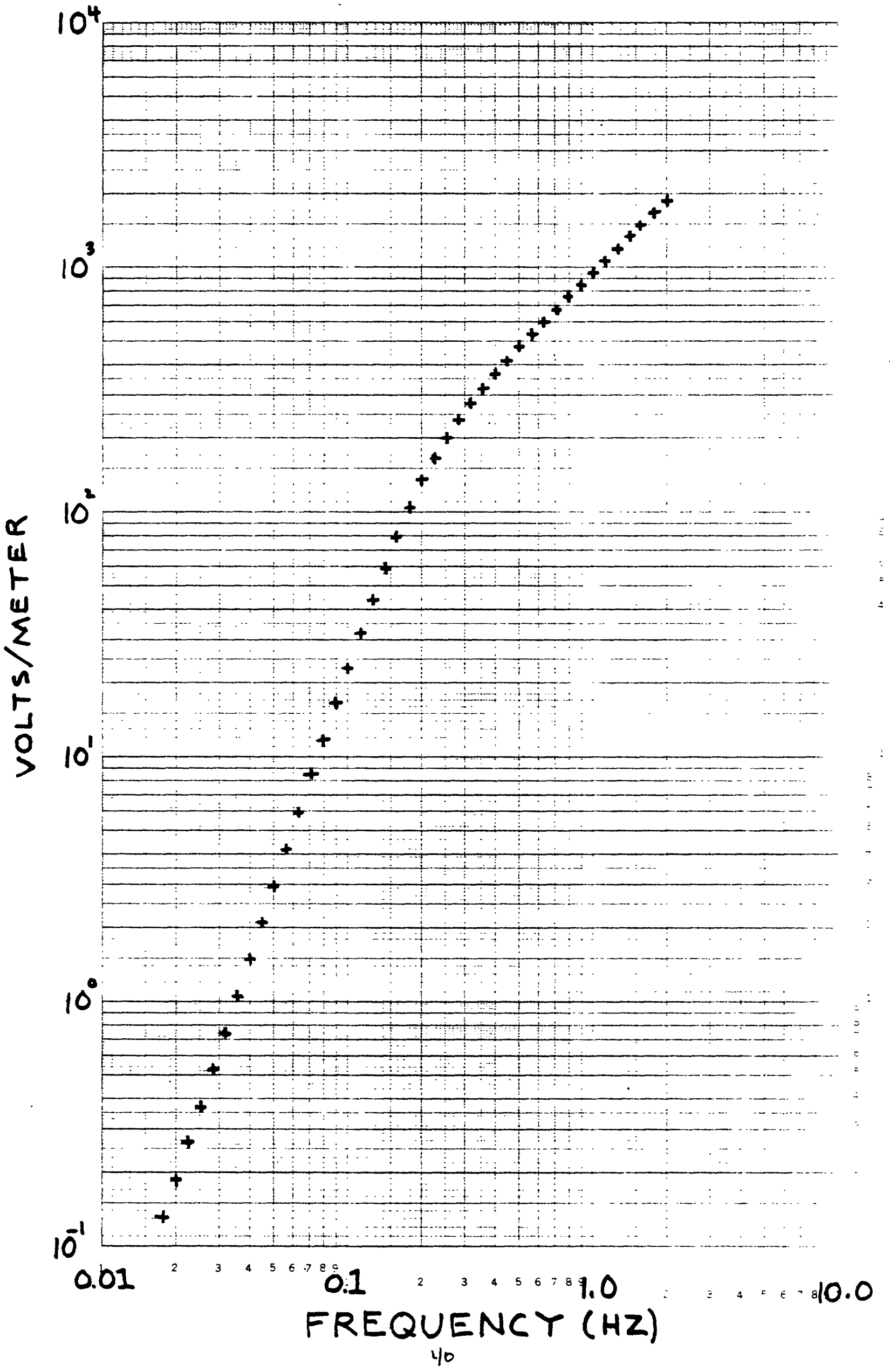




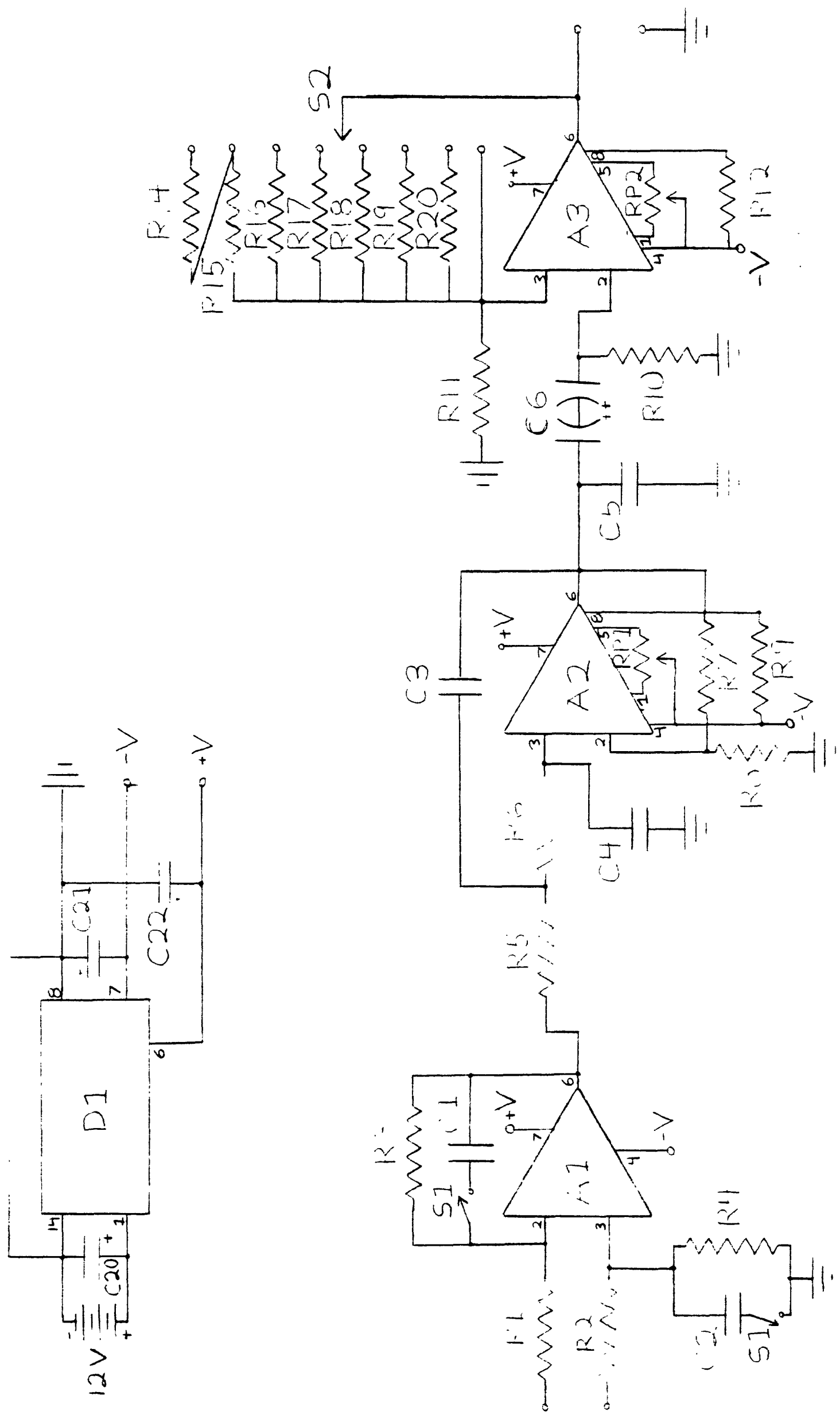




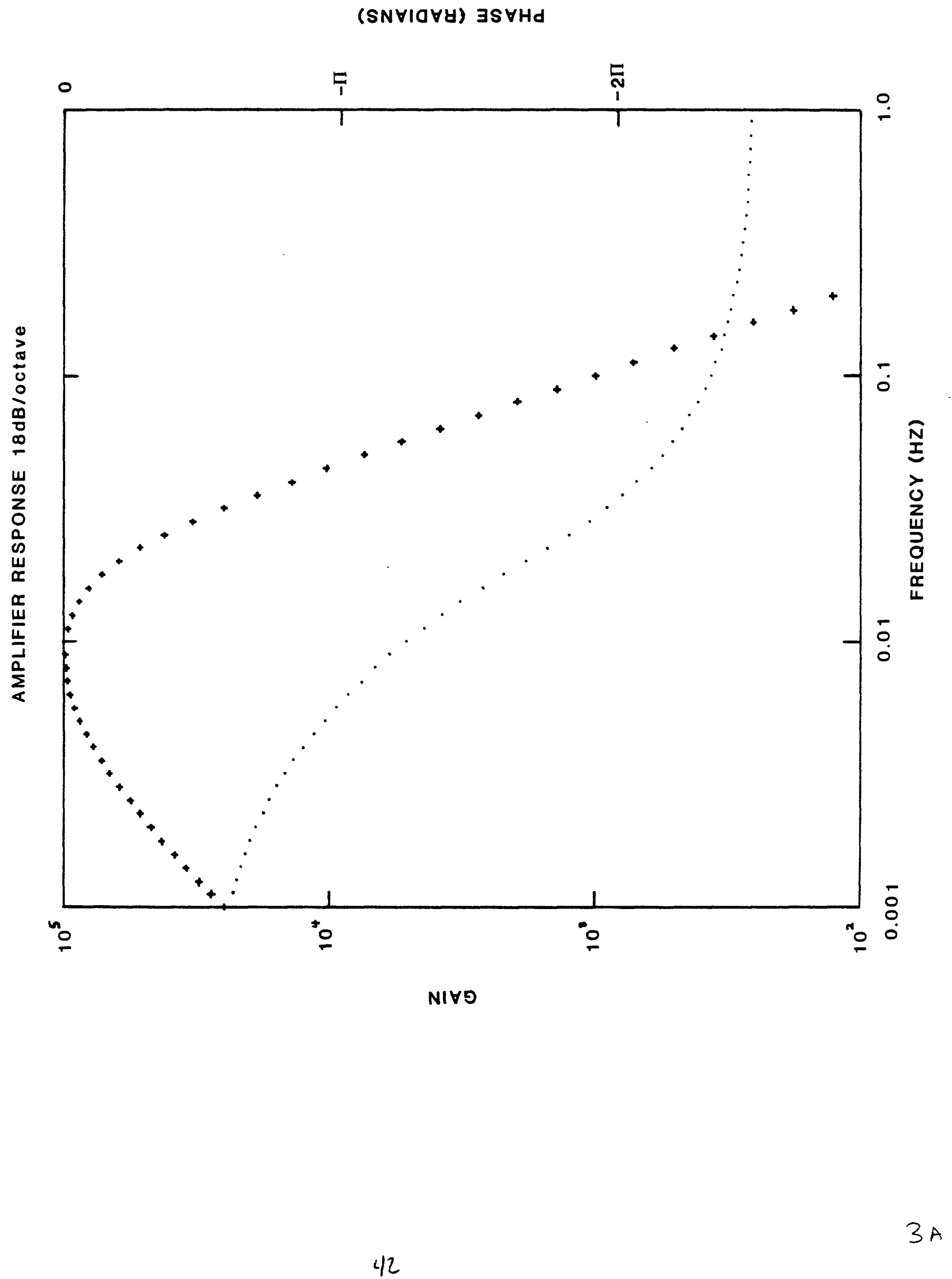




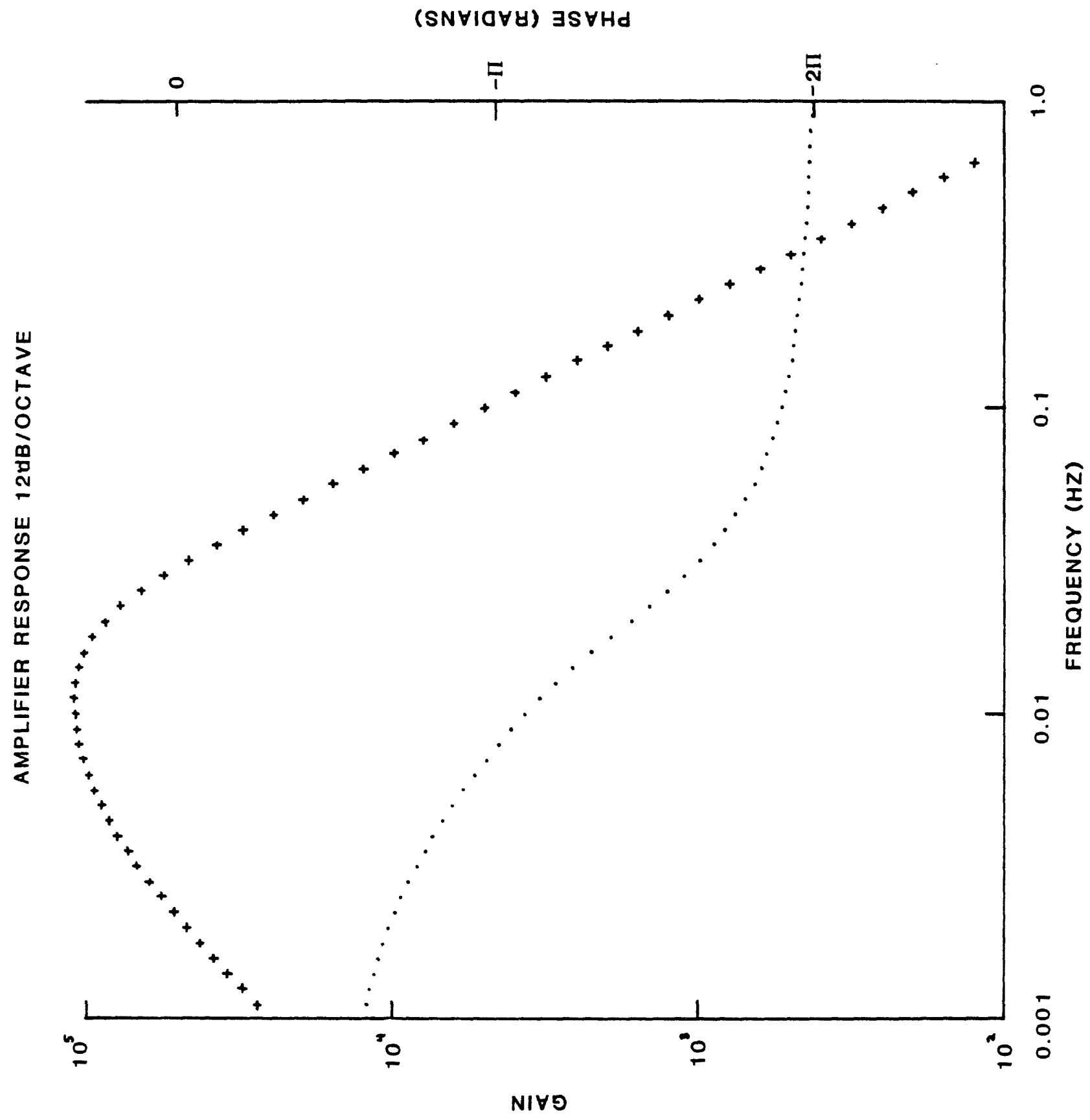

38

43 


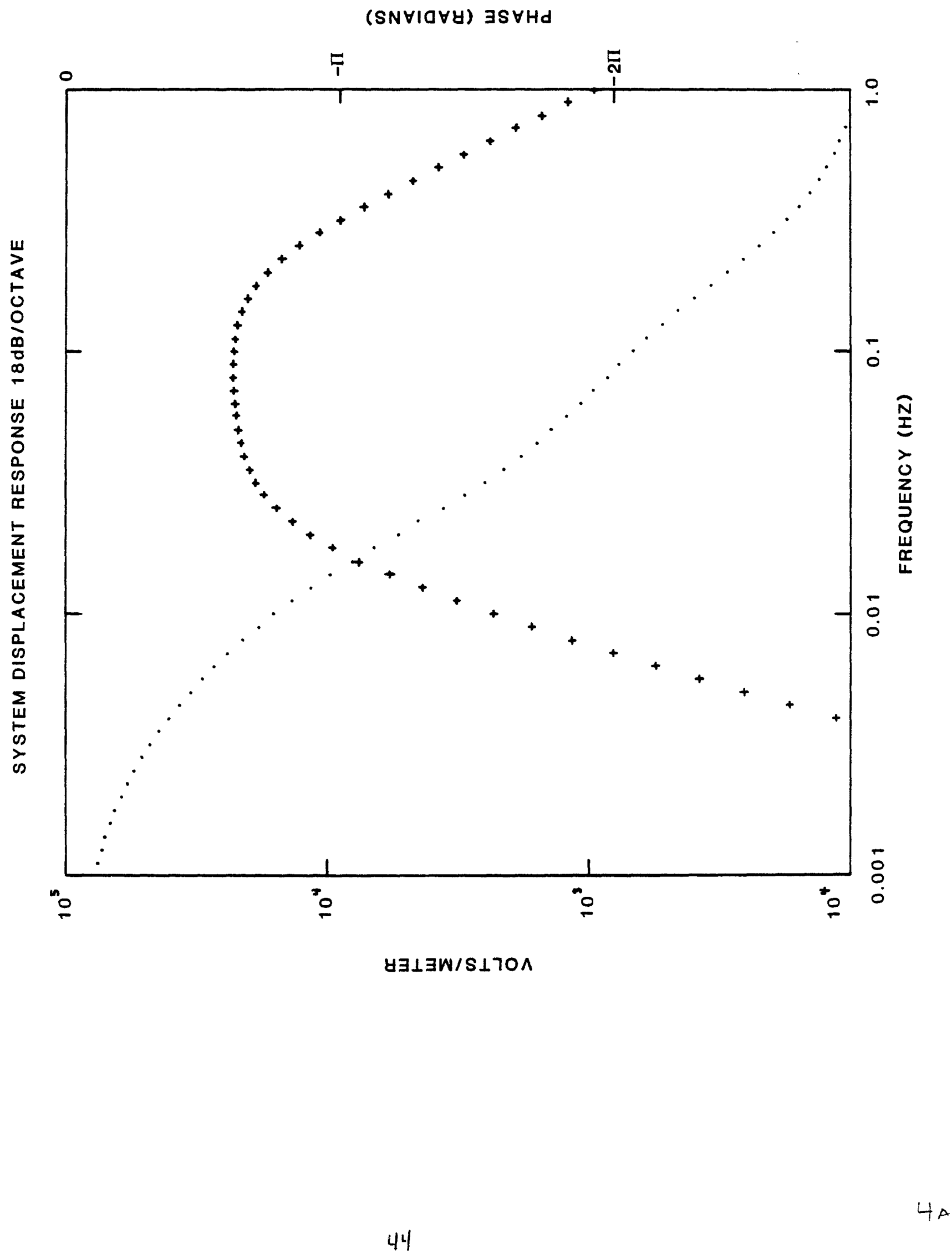




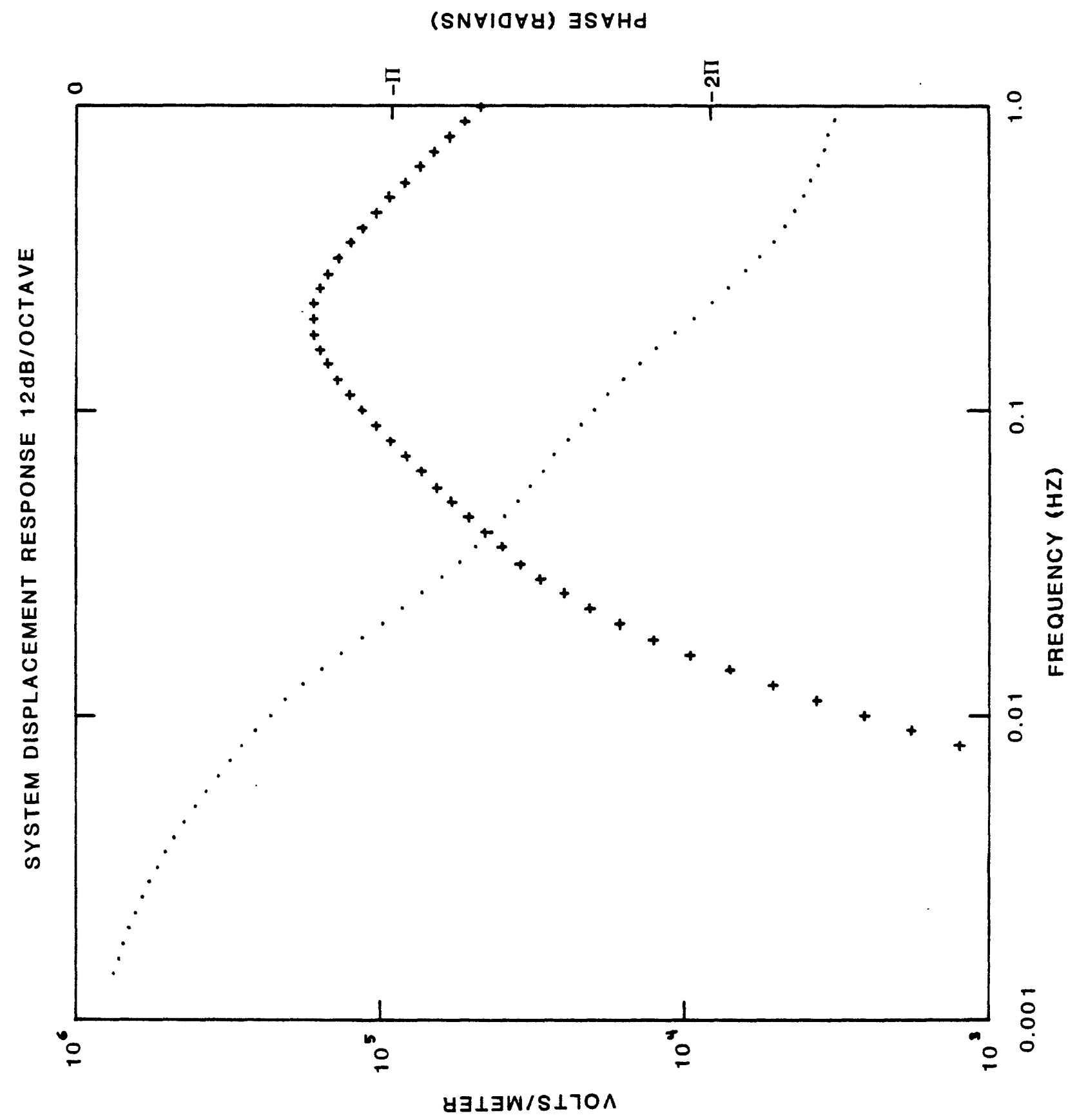




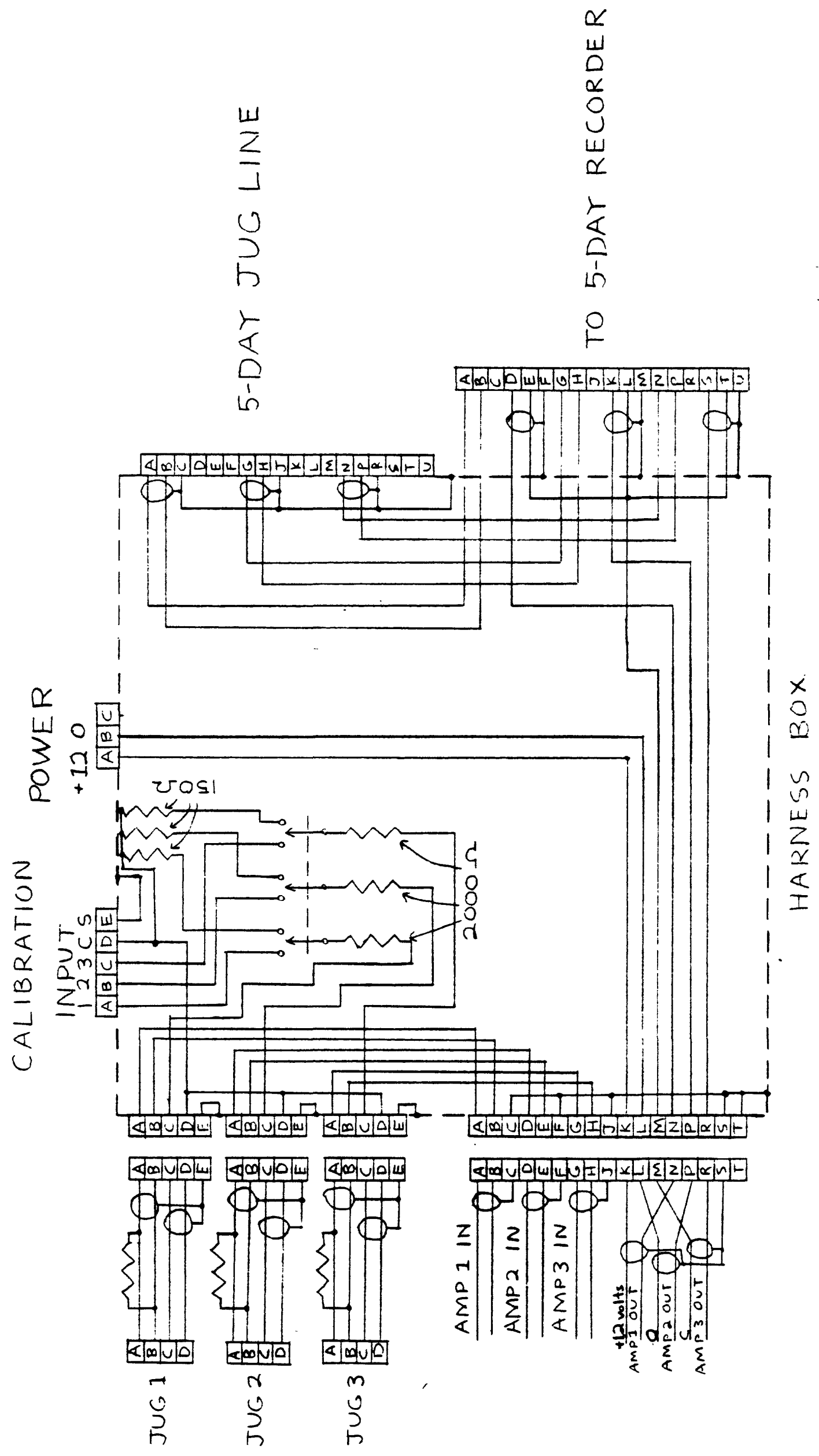




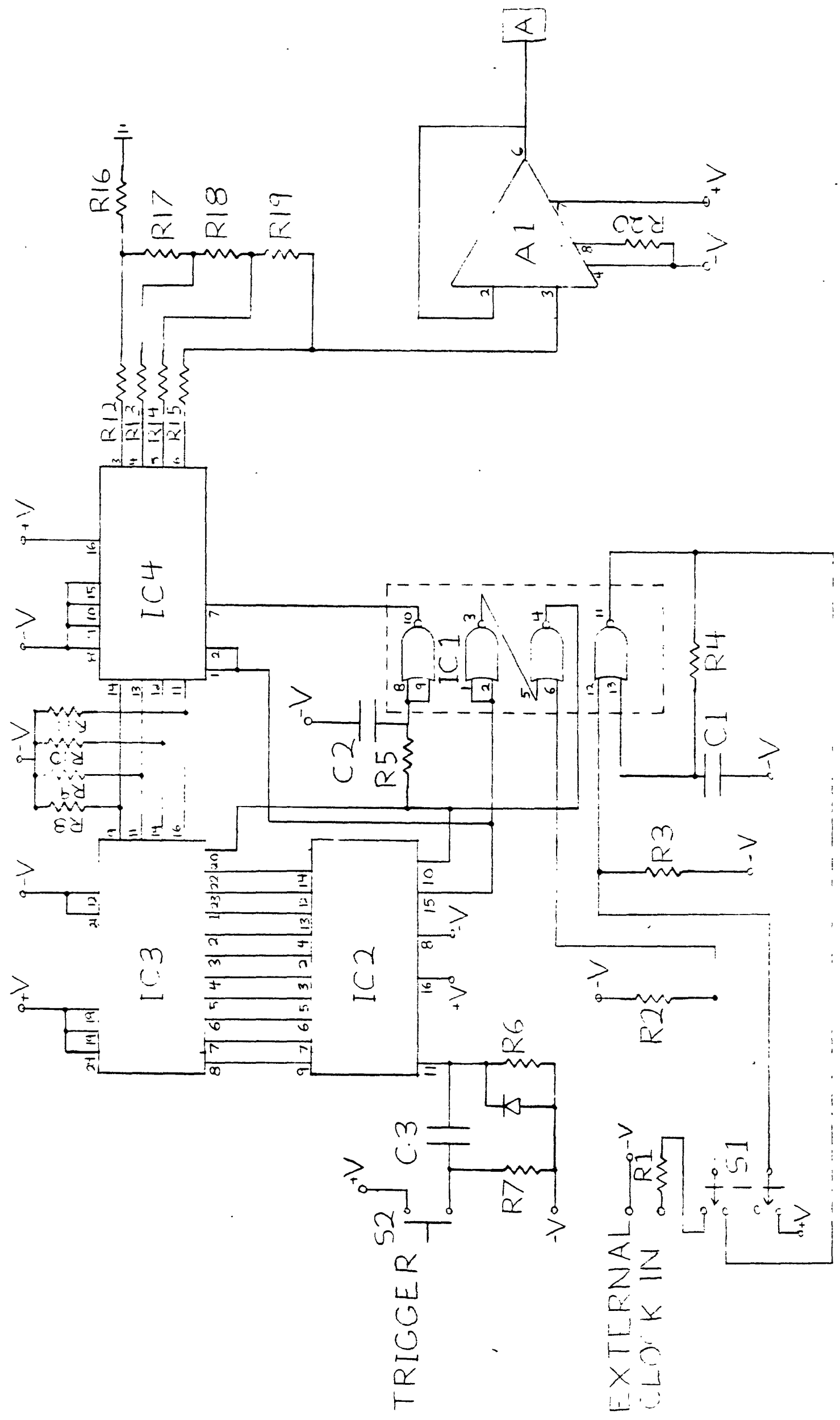



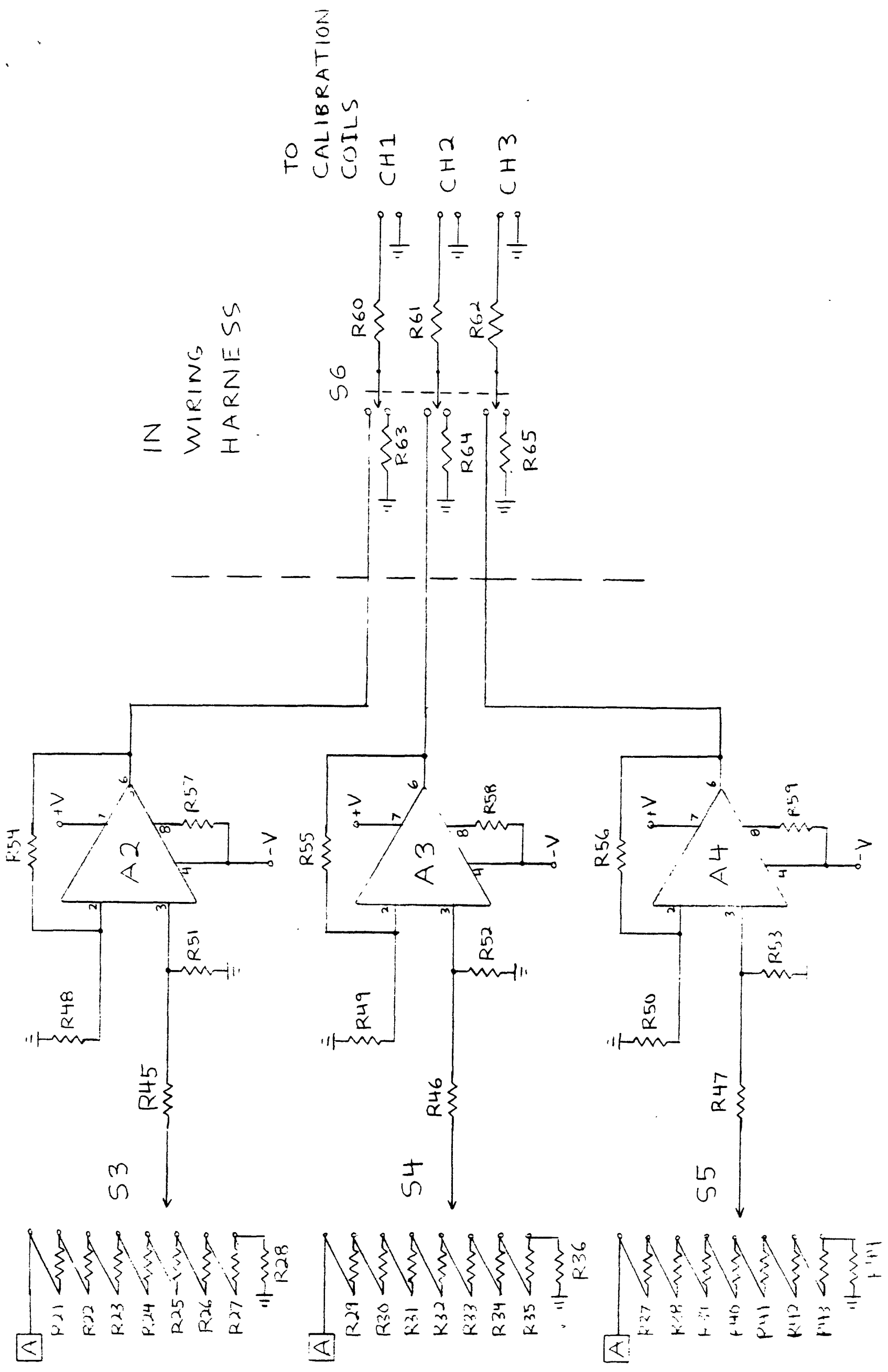


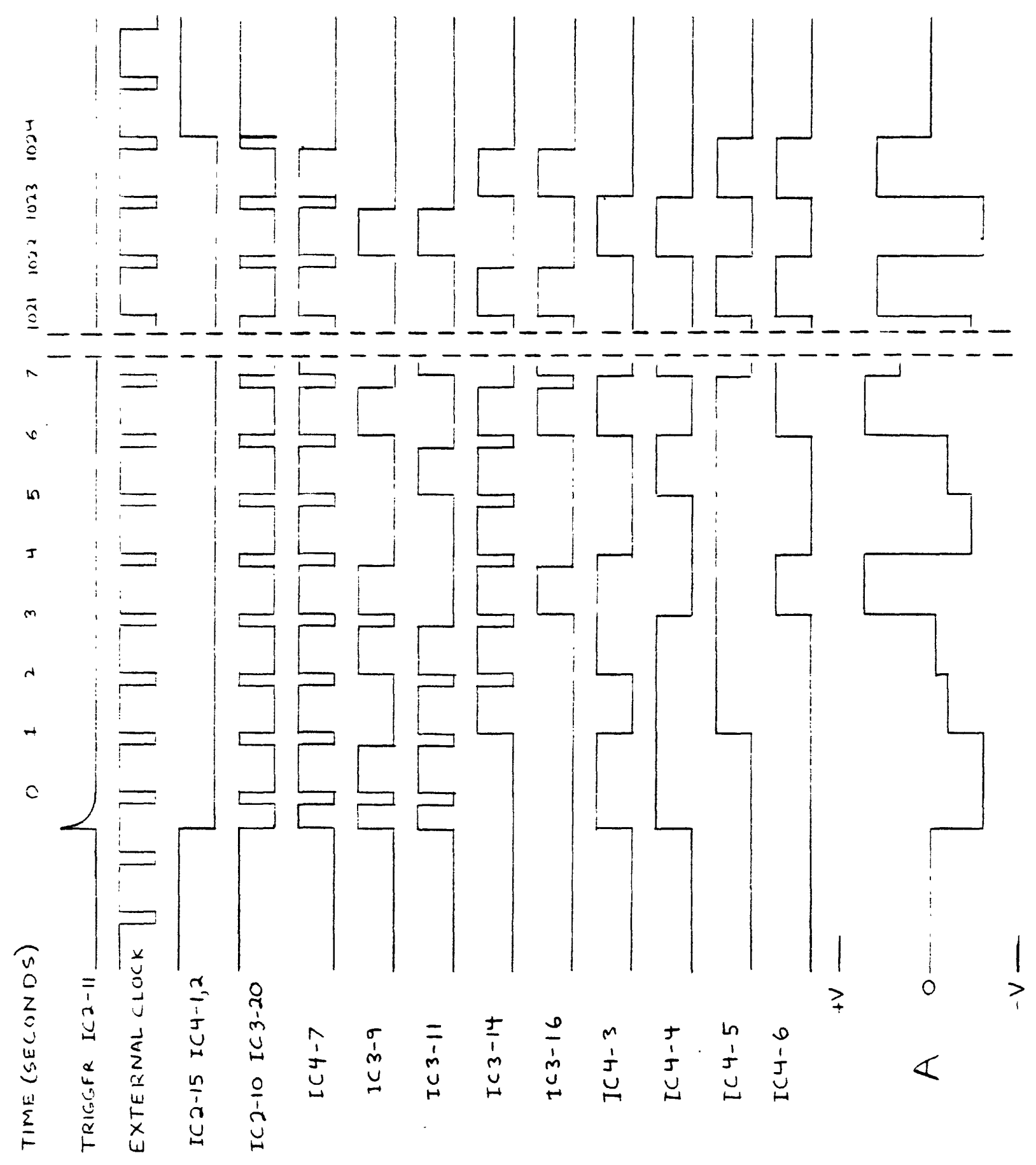




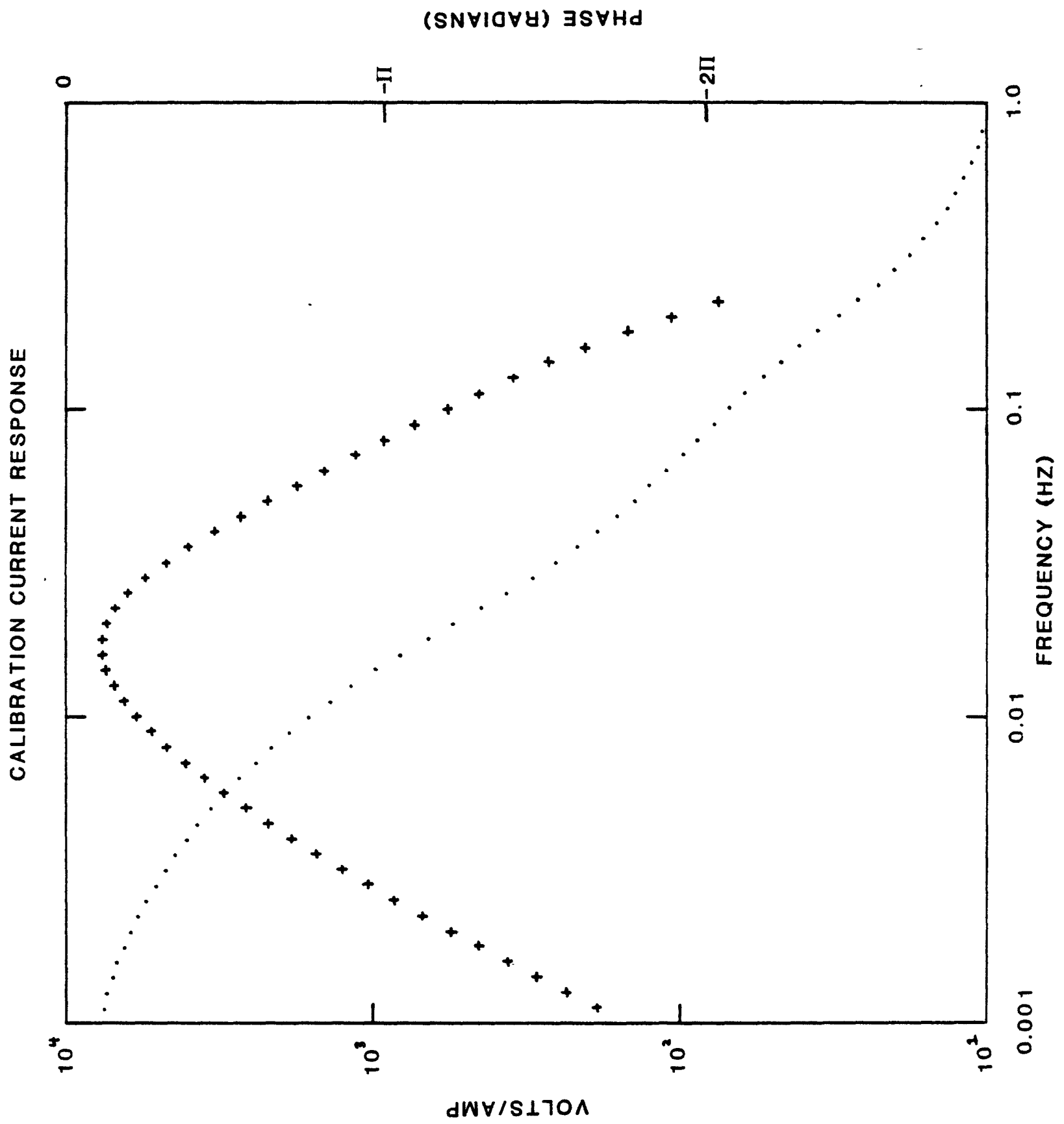

50 

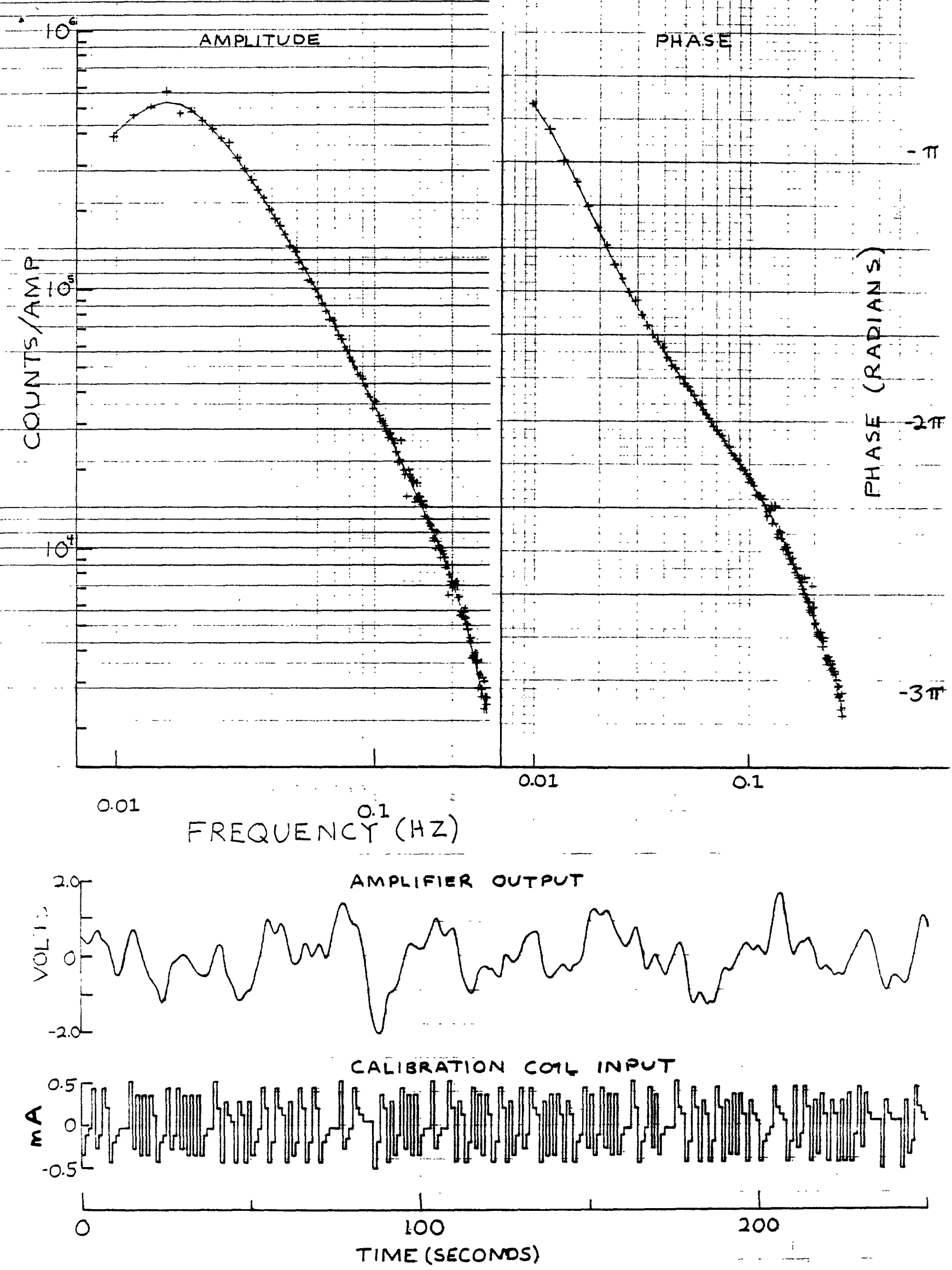
$50-$

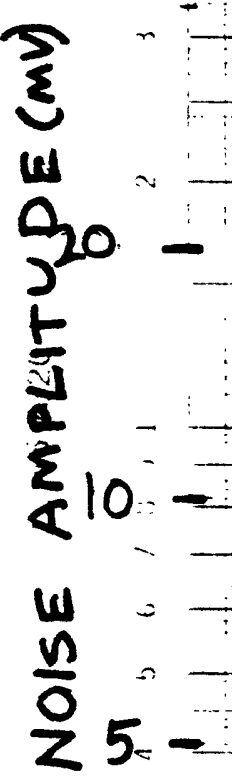

$2=$
$1=$
$0.5=$

$+2+$ 0

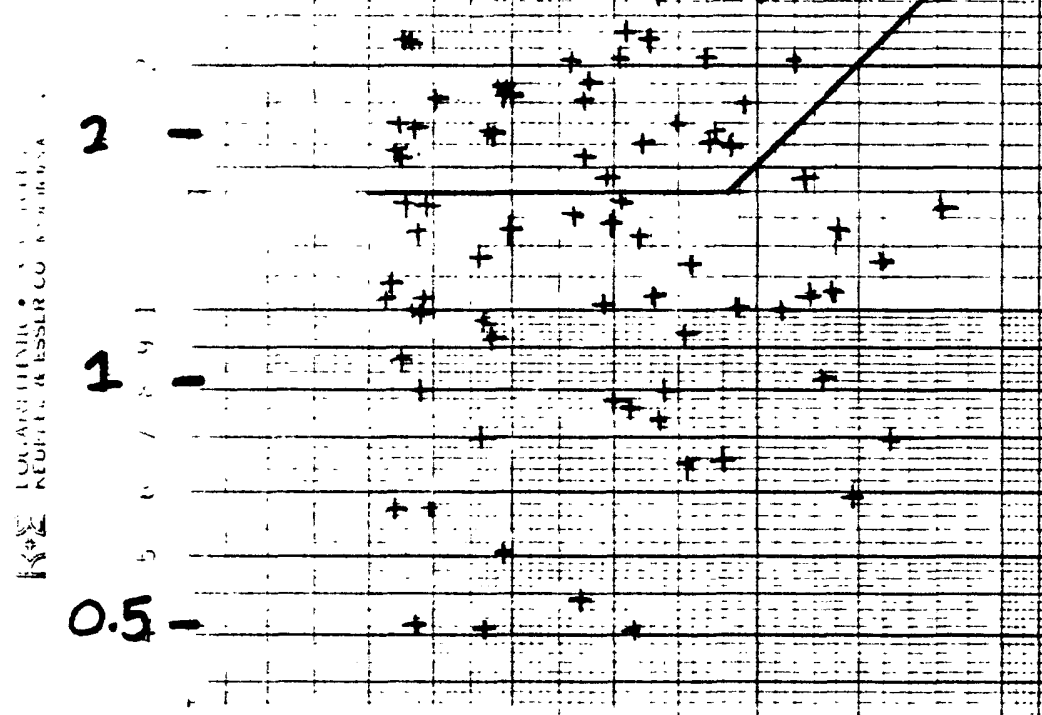

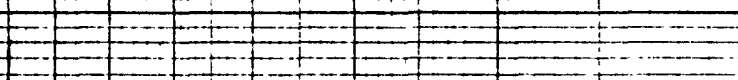




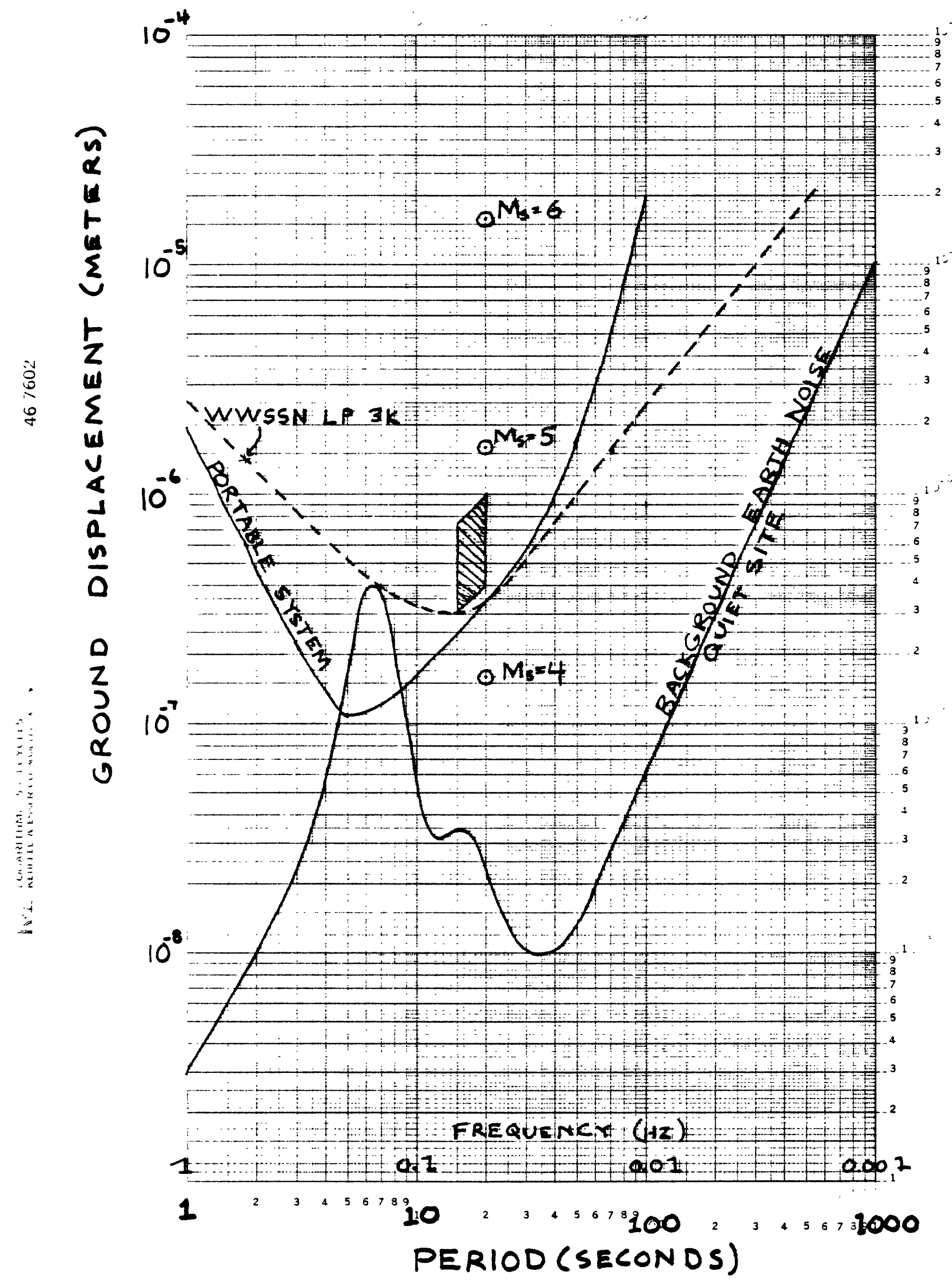




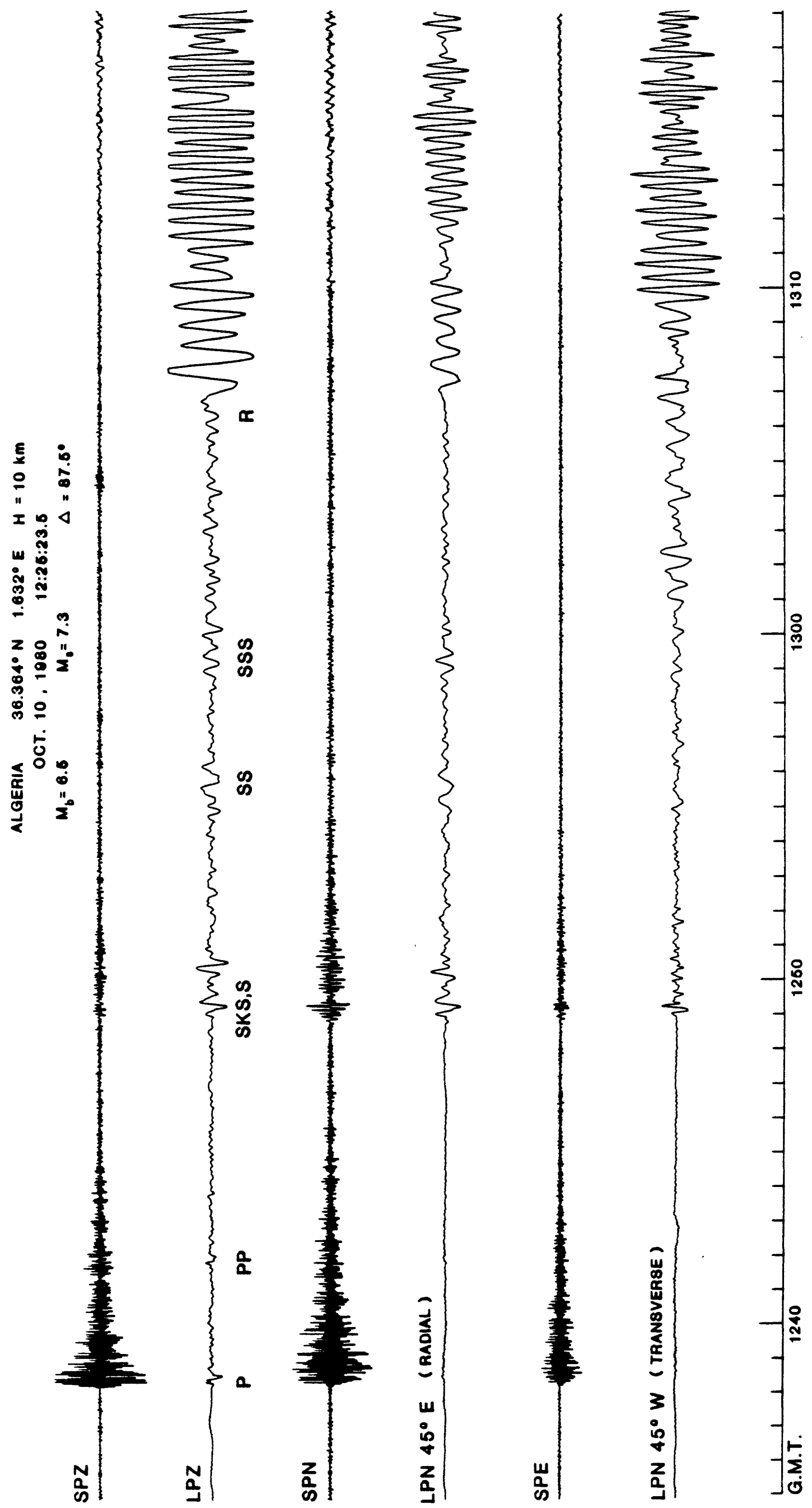

